\title{
GNS Castor V/21 \\ Headspace Gas \\ Sampling 2014
}

P. L. Winston

January 2016

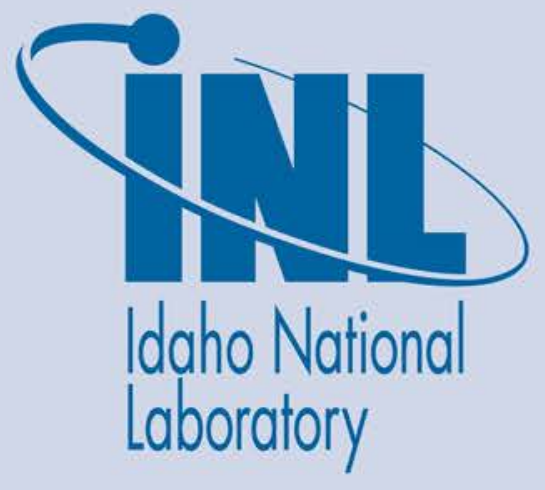

The INL is a U.S. Department of Energy National Laboratory operated by Battelle Energy Alliance 


\section{DISCLAIMER}

This information was prepared as an account of work sponsored by an agency of the U.S. Government. Neither the U.S. Government nor any agency thereof, nor any of their employees, makes any warranty, expressed or implied, or assumes any legal liability or responsibility for the accuracy, completeness, or usefulness, of any information, apparatus, product, or process disclosed, or represents that its use would not infringe privately owned rights. References herein to any specific commercial product, process, or service by trade name, trade mark, manufacturer, or otherwise, does not necessarily constitute or imply its endorsement, recommendation, or favoring by the U.S. Government or any agency thereof. The views and opinions of authors expressed herein do not necessarily state or reflect those of the U.S. Government or any agency thereof. 
INL/EXT-16-37762

Revision 0

\title{
GNS Castor V/21 Headspace Gas Sampling 2014
}

\author{
P. L. Winston
}

January 2016

Idaho National Laboratory Idaho Falls, Idaho 83415

http://www.inl.gov

Prepared for the

U.S. Department of Energy

Office of Nuclear Energy

Under DOE Idaho Operations Office

Contract DE-AC07-05ID14517 



\title{
GNS Castor V/21 Headspace Gas Sampling 2014
}

\author{
INL/EXT-16-37762 \\ Revision 0 \\ January 2016
}

Approved by:

Sindra M. Buk 1.27.16

Name

Date

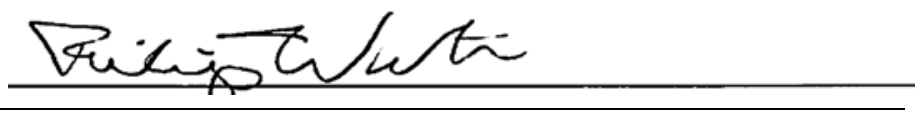

Name

$1-27-16$

Date

Name

Date

Title [optional]

Name

Date

Title [optional] 



\section{ACKNOWLEDGMENTS}

The author would like to acknowledge the assistance of Mr. Mark Arrowood of $\mathrm{CH}-2 \mathrm{M}-\mathrm{WG}$ Idaho in coordinating and managing the sample acquisition and Dr. Steven Marschman of Battelle Energy Alliance for providing program support to acquire and analyze the samples. 


\begin{abstract}
Prior to performing an internal visual inspection, samples of the headspace gas of the GNS Castor V/21 cask at the Idaho National Laboratory were taken on June 12, 2014. These samples were taken in support of the CREIPI/Japanese nuclear industry effort to validate fuel integrity without visual inspection by measuring the ${ }^{85} \mathrm{Kr}$ content of the cask headspace. This report provides the fission product gas data that resulted from sampling in 2014.program as part of the Dry Cask Storage Gas Analysis for Central Research Institute of Electric Power Industry WFO No. 15906.
\end{abstract}




\section{CONTENTS}

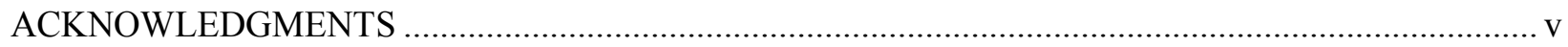

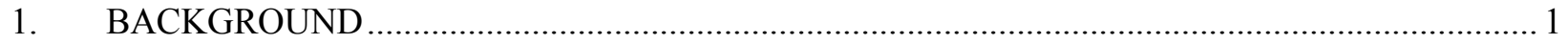

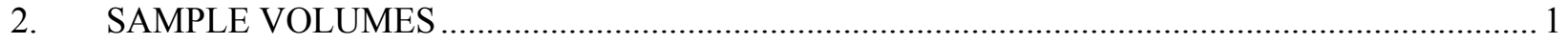

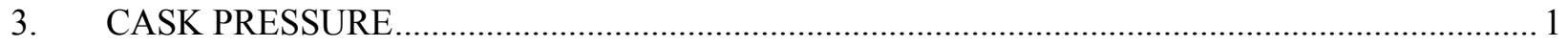

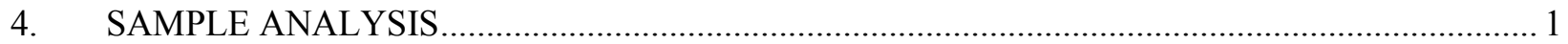

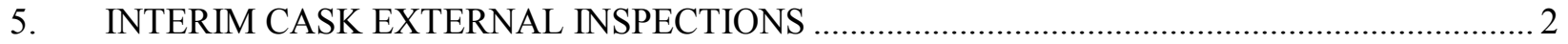

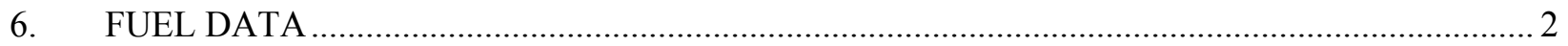

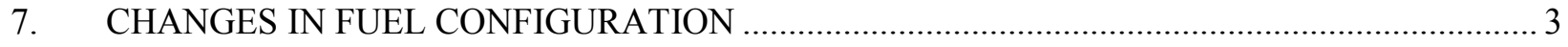

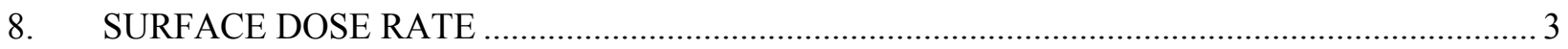

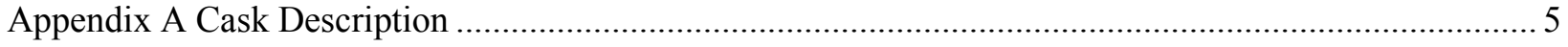

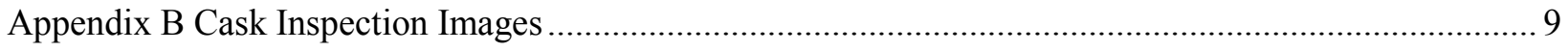

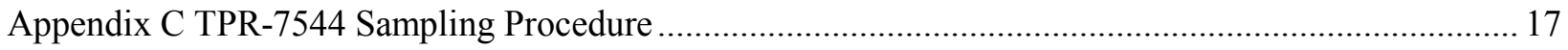




\section{GNS Castor V/21 Headspace Gas Sampling 2014 \\ 1. BACKGROUND}

Prior to performing an internal visual inspection, samples of the headspace gas of the GNS Castor $\mathrm{V} / 21$ cask were taken on June 12, 2014. These samples were taken in support of the CREIPI/Japanese nuclear industry effort to validate fuel integrity without visual inspection by measuring the ${ }^{85} \mathrm{Kr}$ content of the cask headspace. The samples would normally have been taken in 2015 according to the 5-year sampling schedule, but the US Department of Energy requested a demonstration of the technology for inspecting the cask using a borescope camera be done in 2014. The cask headspace sampling program will return to the 5-year schedule for future samples.

\section{SAMPLE VOLUMES}

Three-300 $\mathrm{mL}$ sample volumes were acquired, one sample being nitrogen that is used to purge the sample system, and two samples of the helium-headspace of the cask. One helium sample volume was sent to the Pacific Northwest National Laboratory (PNNL) analytical laboratory, and the nitrogen-filled system blank and the second helium-filled volume was sent to Southwest Research Institute (SWRI) analytical laboratory. The samples were sent to two different laboratories to provide a confirmation of the methods used. The sample volumes were baked out prior to use according to the method used historically, as in 2010 .

\section{CASK PRESSURE}

At the time of sampling, the cask internal pressure was approximately 380 mbars $(0.375 \mathrm{~atm})$, and the cask surface temperature was approximately $85^{\circ} \mathrm{F}\left(29^{\circ} \mathrm{C}\right)$. Following sampling and borescope inspection, the cask was refilled with high performance liquid chromatography (HPLC)-grade helium to a pressure of approximately 600 mbars (1 atm).

\section{SAMPLE ANALYSIS}

Gamma ray spectrometry and mass spectrometry analysis of the samples was performed by each of the analytical laboratories. The analysis included measurement of ${ }^{85} \mathrm{Kr},{ }^{133} \mathrm{Xe}$, and ${ }^{137} \mathrm{Cs} .{ }^{133} \mathrm{Xe}$ is only relevant for fresh fuels, having a 5-day nominal half-life. It has historically been requested for analysis in the dry stored fuel at INL. Mass spectrometry analysis is used to determine the presence of unacceptably high concentrations of hydrogen, and the oxygen-nitrogen ratio for determination of air in leakage.

Analysis by PNNL was per PNNL procedure RPG-CMC-450, Rev. 2, Gamma Energy Analysis and Low Energy Photon Spectrometry, and the SWRI method requested was the same as that used in 2010. PNNL counted the gas sample in duplicate, using $96.9 \mathrm{~mL}$ polyethylene gas cylinders with a method reference blank for 4 days on a $100 \%$ relative efficiency germanium detector. SWRI counted $60 \mathrm{~mL}$ of the sample in duplicate using a 1.2-L Gas Marinelli Beaker for 1 hour.

The PNNL analysis states that, "No gamma emitters were detected above background following a counting time of nearly 4 days on the face of high efficiency HPGe detectors." This count data yielded a minimum detectable activity of less than 3 nanoCuries per liter. $(1.1 \mathrm{E}-1 \mathrm{~Bq} / \mathrm{mL})$.

The reported value for SWRI was less than the minimum detectable activity of $9.71 \mathrm{E} 4 \mathrm{pCi} / \mathrm{L}$, (3.59 Bq/mL).

The sample analysis for hydrogen, helium, nitrogen, oxygen, argon, and carbon dioxide indicated that there is effectively no detectable hydrogen, and therefore, no corrosion is caused by a reaction of retained water. Hydrogen was not detected by the gas chromatographic method used by SWRI. Hydrogen was detected at the 1E-3 mole percent concentration by the gas mass spectrometric method used by PNNL. No water was detected in the PNNL analysis. 
The conclusion of these two analyses is that there was no detectable ${ }^{85} \mathrm{Kr}$ in the cask headspace samples. Based on the low value of the minimum detectable activity and the nondetection, it can be concluded that the fuel cladding is gas tight, not releasing any fission gases, and therefore, can be classified as intact fuel.

The final reports for both the PNNL and SWRI analyses are provided as separate attachments because of the challenge of importing Adobe .pdf documents into this Microsoft Word document.

\section{INTERIM CASK EXTERNAL INSPECTIONS}

Since the last sampling in 2010, visual inspections and manual data recording of pressure and temperature have been done every other week in accordance with form FRM-1708. With the exception of the inter-lid pressure of the TN-24P cask, all pressure values are of the internal pressure of the cask.

Sampling of the cask headspace is mandated by the safety analysis report SAR-112 to verify that the cask atmosphere does not accumulate flammable concentrations of hydrogen gas. Analysis for gaseous radionuclides is not mandated by safety analysis, and is performed to provide information on fuel integrity.

The sampling was performed using the same equipment as in previous years, using sample containers that were treated in the same manner as in previous years, and following the same procedure as in previous years with editorial changes reflecting 2014 personnel responsibilities.

The casks are not moved under normal circumstances, although in the 1999 inspection, the cask was moved from the TAN-791 pad, and an indication of rust was noted on the concrete under the Castor cask. Because of the thickness of the cask wall and the noncorrosive storage environment, there is no corrosion allowance for this cask.

\section{FUEL DATA}

Percent burnup is based on the amount of initial ${ }^{235} \mathrm{U}$ consumed by irradiation. Primary information is provided by the original shipper.

\begin{tabular}{|c|c|c|c|c|c|c|c|c|c|c|}
\hline & & GNS Castor & $\mathrm{r} V / 21$ INL S & Stored Comr & al Fuel Data & & & & & \\
\hline Pre-Irradia & ation & & & & Irradiation & Data & & & & \\
\hline $\begin{array}{l}\text { FHU Unique } \\
\text { ID Number }\end{array}$ & $\begin{array}{l}\text { Unique ID } \\
\text { Number } \\
\text { (ANSI No.) }\end{array}$ & U kg & U.235 kg & U-238 kg & $\begin{array}{l}\text { Burnup } \\
\text { (MWd/MT } \\
\text { HM) }\end{array}$ & $\begin{array}{l}\text { Discharge } \\
\text { Date }\end{array}$ & $\begin{array}{l}\text { Power } \\
\text { Level(MW } \\
\text { th) }\end{array}$ & $\begin{array}{l}\text { Years } \\
\text { Decayed }\end{array}$ & $\begin{array}{l}\text { Percent } \\
\text { Burnup }\end{array}$ & $\begin{array}{l}\text { Decay Heat } \\
\text { (watts) as } \\
\text { of } \\
01 / 01 / 1990\end{array}$ \\
\hline T03 & LM02JJ & 457.1 & 14.2 & 442.9 & 35,722 & $11 / 6 / 81$ & 2441 & 33.2 & 78.9 & 627 \\
\hline T07 & LMO2JL & 457.1 & 14.2 & 442.9 & 35,722 & $11 / 6 / 81$ & 2441 & 33.2 & 78.9 & 627 \\
\hline T08 & LM02JM & 457.1 & 14.2 & 442.9 & 35,722 & $11 / 6 / 81$ & 2441 & 33.2 & 78.9 & 627 \\
\hline T09 & LM02JU & 457.1 & 14.2 & 442.9 & 35,722 & $11 / 6 / 81$ & 2441 & 33.2 & 78.9 & 627 \\
\hline T11 & LM02JR & 457.1 & 14.2 & 442.9 & 35,722 & $11 / 6 / 81$ & 2441 & 33.2 & 78.9 & 627 \\
\hline T12 & LMO2JP & 457.1 & 14.2 & 442.9 & 35,722 & $11 / 6 / 81$ & 2441 & 33.2 & 78.9 & 627 \\
\hline T13 & LM02JY & 457.8 & 14.2 & 443.6 & 35,722 & $11 / 6 / 81$ & 2441 & 33.2 & 78.93 & 627 \\
\hline T16 & LM02JN & 457.8 & 14.2 & 443.6 & 35,722 & $11 / 6 / 81$ & 2441 & 33.2 & 78.93 & 627 \\
\hline V01 & LM041 D & 457.5 & 13.3 & 444.2 & 30,214 & $6 / 30 / 83$ & 2441 & 31.5 & 73.4 & 585.3 \\
\hline V04 & LM041 F & 457.5 & 13.3 & 444.2 & 31,146 & $11 / 6 / 81$ & 2441 & 33.2 & 74.5 & 537.1 \\
\hline V05 & LM0425 & 457.5 & 13.3 & 444.2 & 31.511 & $11 / 6 / 81$ & 2441 & 33.2 & 75.09 & 544.3 \\
\hline V08 & LM0428 & 457.5 & 13.3 & 444.2 & 31,146 & $6 / 30 / 83$ & 2441 & 31.5 & 74.57 & 537.1 \\
\hline V09 & LM0423 & 457.5 & 13.3 & 444.2 & 30,214 & $6 / 30 / 83$ & 2441 & 31.5 & 73.56 & 585.3 \\
\hline \begin{tabular}{|l|} 
V11 \\
\end{tabular} & LM042A & 457.5 & 13.3 & 444.2 & 29,823 & $6 / 30 / 83$ & 2441 & 31.5 & 73.26 & 575.5 \\
\hline V12 & LM042C & 457.5 & 13.3 & 444.2 & 31,146 & $6 / 30 / 83$ & 2441 & 31.5 & 74.59 & 537.1 \\
\hline V13 & LM0413 & 457.5 & 13.3 & 444.2 & 29,823 & $6 / 30 / 83$ & 2441 & 31.5 & 72.64 & 575.5 \\
\hline V14 & LM041 L & 457.5 & 13.3 & 444.2 & 29,823 & $6 / 30 / 83$ & 2441 & 31.5 & 72.93 & 575.5 \\
\hline V15 & LM042D & 457.5 & 13.3 & 438.9 & 29,823 & $6 / 30 / 83$ & 2441 & 31.5 & 72.73 & 575.5 \\
\hline V24 & LM042G & 457.5 & 13.3 & 438.1 & 31,146 & $11 / 6 / 81$ & 2441 & 33.2 & 74.57 & 537.1 \\
\hline V25 & LMO40H & 457.5 & 13.3 & 438.7 & 30,214 & $6 / 30 / 83$ & 2441 & 31.5 & 73.15 & 585.3 \\
\hline V27 & LM0416 & 457.5 & 13.3 & 438.6 & 30.214 & $6 / 30 / 83$ & 2441 & 31.5 & 73.46 & 585.3 \\
\hline
\end{tabular}




\section{CHANGES IN FUEL CONFIGURATION}

Twelve centrally located rods were removed from Assembly T11 in 1999 for nondestructive and destructive evaluation. Results of the destructive analysis of three of the rods may be found in Examination of Spent PWR Fuel Rods After 15 Years in Dry Storage, R. E. Einziger, H. C. Tsai, M. C. Billone, and B. A. Hilton, Paper No. ICONE10-22456, pages 351-358. The nine remaining intact rods were placed in a basket that is presently stored in the REA-2023 cask on the CPP-2707 pad.

\section{SURFACE DOSE RATE}

The nominal surface dose measured in 2014 was $2 \mathrm{mR} / \mathrm{hr}$ beta-gamma and $3 \mathrm{mR} / \mathrm{hr}$ neutron at contact. 


\title{
Appendix A Cask Description
}

\subsubsection{Cask Body}

\author{
From SAR-112
}

The cask body is a one piece cylindrical structure composed of ductile cast iron in nodular graphite form. This material exhibits good strength and ductility, as well as providing effective gamma shielding. The overall external dimensions of the cask body are $4886 \mathrm{~mm}(16 \mathrm{ft})$ high and $2385 \mathrm{~mm}(8 \mathrm{ft})$ in diameter (Figure 1-1). The external surface has 73 heat transfer fins that run circumferentially around the cask and is coated with epoxy paint for corrosion protection and ease of decontamination.

The cask body wall, excluding fins, is $380 \mathrm{~mm}$ (15 in.) thick. Incorporated within the wall of the body are polyethylene moderator rods to provide neutron shielding. Two concentric rows of these $60-\mathrm{mm}$ (2.3-in.) nominal diameter rods are distributed around the cask perimeter (Figure 1-2). Two lifting trunnions are bolted on each end of the cask body. The diameter of the inner cavity is $1527 \mathrm{~mm}(5 \mathrm{ft})$, and the overall inner cavity length is $4152 \mathrm{~mm}$ (163 in.). Precision-machined surfaces are provided at the open end of the cask cavity for positive gasket sealing, and bolt holes are included at these locations to secure the two cask lids. The interior cavity surfaces, including sealing surfaces, have a galvanic-applied nickel plating.

\subsubsection{Spent Fuel Basket}

The spent fuel basket (Figure 1-2) is a cylindrical structure of welded stainless steel plate and borated stainless steel plate, having a boron content of approximately $1 \%$ for criticality control. The basket comprises an array of 21 square fuel tubes/channels that provide structural support and positive positioning of the fuel assemblies. The basket overall height is $4110 \mathrm{~mm}(13.5 \mathrm{ft})$ including the four 130-mm-diameter (5-in.) pedestals that support the basket and fuel weight on the bottom of the cask cavity. The basket outside diameter of $1524 \mathrm{~mm}(5 \mathrm{ft})$ fits tightly in the cask cavity inner diameter of $1527 \mathrm{~mm}(5 \mathrm{ft})$. The depth of each fuel tube is $4050 \mathrm{~mm}(13.3 \mathrm{ft})$. A spacing of $74 \mathrm{~mm}(3 \mathrm{in}$.) is present between the top of the basket cavity and the underside of the primary lid, thus accommodating a fuel assembly length of $4124 \mathrm{~mm}$ (162 in.) and supporting convection heat transfer. The final assembly results in a clearance of approximately $60 \mathrm{~mm}$ (2.3 in.) between the top of the fuel assemblies and the bottom of the primary lid, for a reference fuel assembly of $4064 \mathrm{~mm}$ (160 in.). The basket layout results in inter-fuel tube spaces that act as flux traps for criticality control and channels to support free convection heat transfer. The basket design ensures a subcritical configuration under worst-case conditions, and the basket structure physically protects the fuel under normal and accident conditions.

A pipe with an inner diameter of $42 \mathrm{~mm}$ (1.6 in.) and a lead-in funnel at the top are welded to the side of a fuel tube near the outer circumference of the basket. The pipe location corresponds to a penetration in the primary lid and the low side of the slope in the cask cavity bottom. The pipe provides a path for a flanged pipe used to fill and drain the cask.

\subsubsection{Primary Lid}

A stainless steel primary lid, $1785 \mathrm{~mm}(6 \mathrm{ft})$ in diameter and $290 \mathrm{~mm}(12 \mathrm{in}$.$) thick, is provided$ (Figure 1-3). Forty-four bolt holes are machined near the lid perimeter to secure the lid to the cask body. Two grooves machined around the lid underside, inside the bolt circle, are provided for O-ring seals (Figure 1-4). The inner groove accepts a metal "C" shaped O-ring, which serves as the first barrier between stored fuel and the environment. The outer grove accepts an elastomer O-ring. A 10-mm-diameter (0.4-in.) penetration through the lid provides access to the annulus between the two seals to perform post-assembly leak testing. This penetration is plugged when not in use. Three penetrations through the lid are provided for various cask operations. A 35-mm-diameter (1.4-in.) straight-through penetration is used for water fill/drain operations. This penetration is located near the perimeter of the lid 
and is normally sealed with two flanges equipped with elastomer O-rings. This location corresponds to the pipe attached to the fuel basket. The other two penetrations, spaced next to each other and covered by a single flange, are also located near the lid perimeter, but 180 degrees from the fill/drain penetration. The through-lid penetration at this location is equipped with a quick-disconnect fitting used for vacuum drying and backfilling with gas. The second penetration at this location leads to the lower edge of the lid.

Although not needed for the CASTOR-V/21, this penetration could be used for leak-testing an optional third lid gasket. This penetration is sealed by a gasketed seal plug in addition to the top cover flange. The primary lid used during 1985 testing was not a standard lid and has 10 additional penetrations for fuel assembly guide tube instrumentation (thermocouple [TC] lances). The pattern of the 10 fuel assembly instrumentation penetrations was selected to measure radial temperature profiles across the basket in the spent fuel assemblies.

\subsubsection{Secondary Lid}

The Secondary Lid, used in commercial application, was not used during the 1985 CASTOR V/21 cask performance test or the long term storage monitoring program conducted during 1994 through 1999, because of interference with fuel assembly instrument leads and the repeated removal and handling of the secondary lid for gas sampling activities. The following functional description of the Secondary Lid is provided for completeness. The stainless steel secondary lid is $2007 \mathrm{~mm}$ (79 in.) in diameter and $90 \mathrm{~mm}$ (3.5 in.) thick (Figure 1-4). Forty-eight bolt holes are machined near the lid perimeter to secure the lid to the cask body. Two concentric grooves located inside the bolt circle on the underside are provided for a metal O-ring/elastomer O-ring sealing system of the same design as that used on the primary lid. Three normally sealed penetrations are provided for various cask operations (Figure 1-4). A 10-mm-diameter (0.4-in.) penetration through the lid provides access to the annulus between the two seals for postassembly seal testing. A gasketed seal plug is used to close this penetration. A second penetration is equipped with a quick-disconnect fitting, which is used for vacuum drying and gas backfilling of the primary/secondary inter-lid space. A 130-mm-diameter (5-in.) cover plate and gasket secured by six $12-\mathrm{mm}(0.5-\mathrm{in}$.) bolts is in place when this penetration is not used. The third penetration provides a pressure sensing port between the inner-lid space and a pressure switch mounted in the secondary lid. The pressure switch is the primary component of the cask seal monitoring system. Due to the secondary lid not being used dose rates discussed in Section 3 were obtained on the primary lid exterior surface. Addition of the secondary lid will greatly reduce measured gamma dose rate values.

The fuel basket is a cylindrical barrel that is partitioned into an array of 21 square fuel tubes in a quadrant layout. The basket is fabricated from welded stainless steel and borated stainless steel plate for criticality control; the borated steel contains approximately $1 \%$ boron. Each fuel tube is separated from the adjacent tube by channels that act as flux traps for criticality control and as channels for convective heat transfer. The basket has an outer diameter of $1524 \mathrm{~mm}(5 \mathrm{ft})$ and a gross depth of $4110 \mathrm{~mm}(13.5 \mathrm{ft})$, including the four $130 \mathrm{~mm}$ ( $5 \mathrm{in}$.) diameter pedestals at the bottom of the basket. The basket barrel fits snugly within the cask with a clearance of only $3 \mathrm{~mm}(0.12 \mathrm{in}$.) total and $74 \mathrm{~mm}(3 \mathrm{in}$.) between the bottom of the primary lid and the top of the basket. 


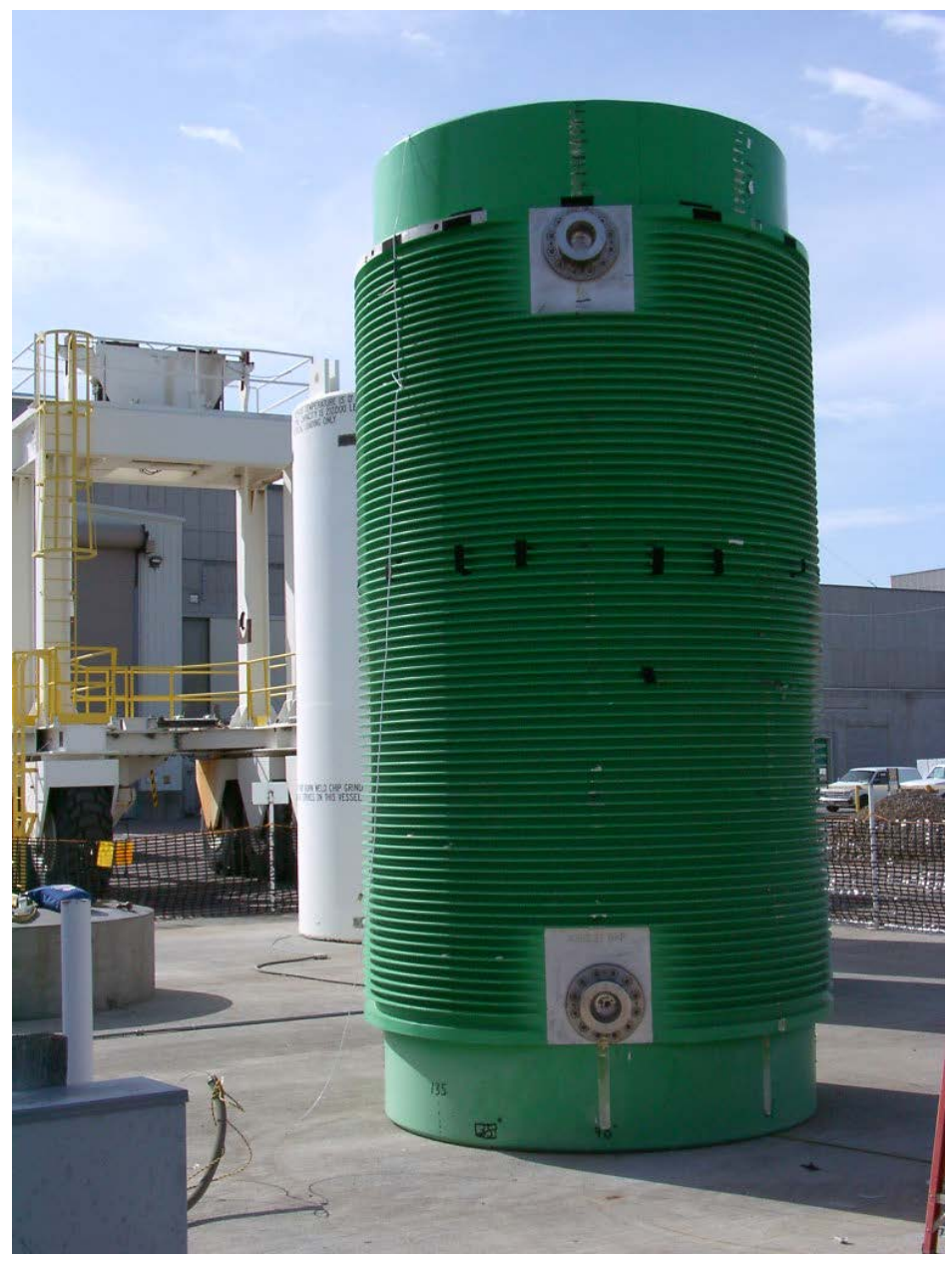

Castor V/21 Cask at the TAN-791 pad 


\section{Appendix B Cask Inspection Images}

A General Electric Mentor Visual iQ Video Borescope with $6.1 \mathrm{~mm}$ probe was used for the port inspection of the GNS Castor V/21 cask. Images from the inspection are shown below. A weld crack in the basket is visible in the first 4 images. The crack varies between 0.015 and 0.019 inches $(0.38$ to $0.48 \mathrm{~mm}$ )

Examples of basket weld cracks have been identified in lid-off inspections in 1985 and 1999 as shown in the graphic from Report INEEL/EXT-01-00183. No correlation has been made in this document between previously identified cracks and those inspected in 2014.

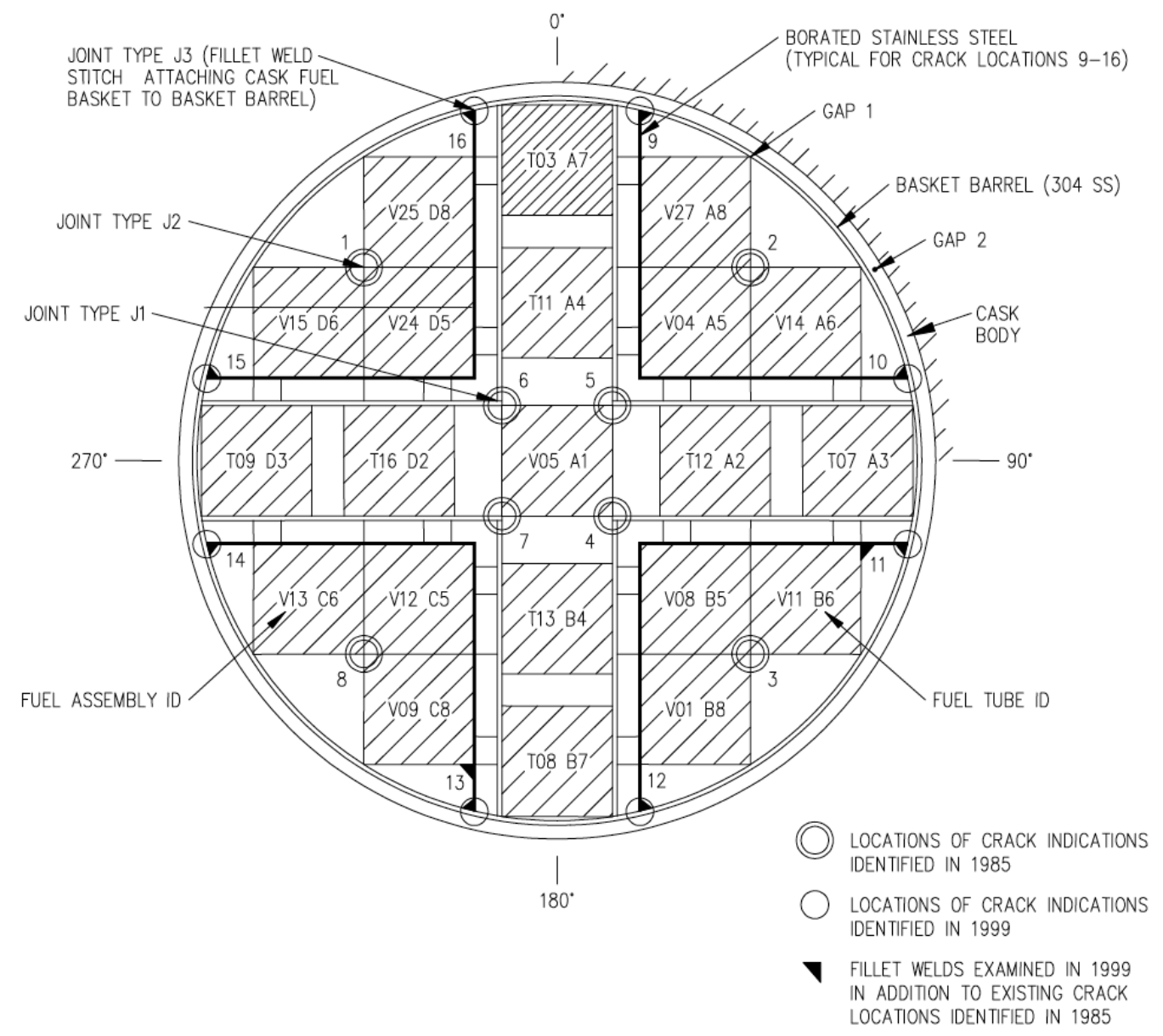




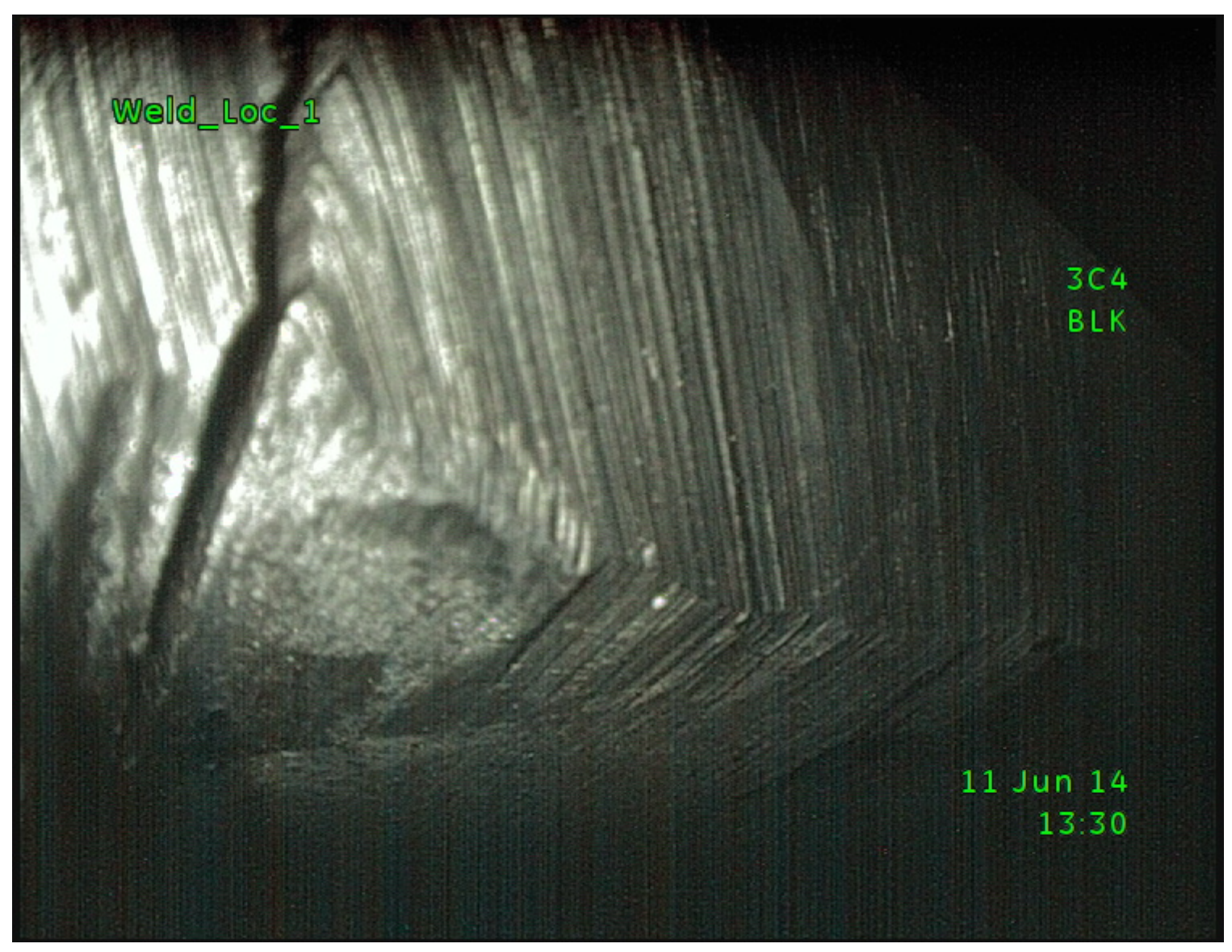

WELD LOC 1_01 


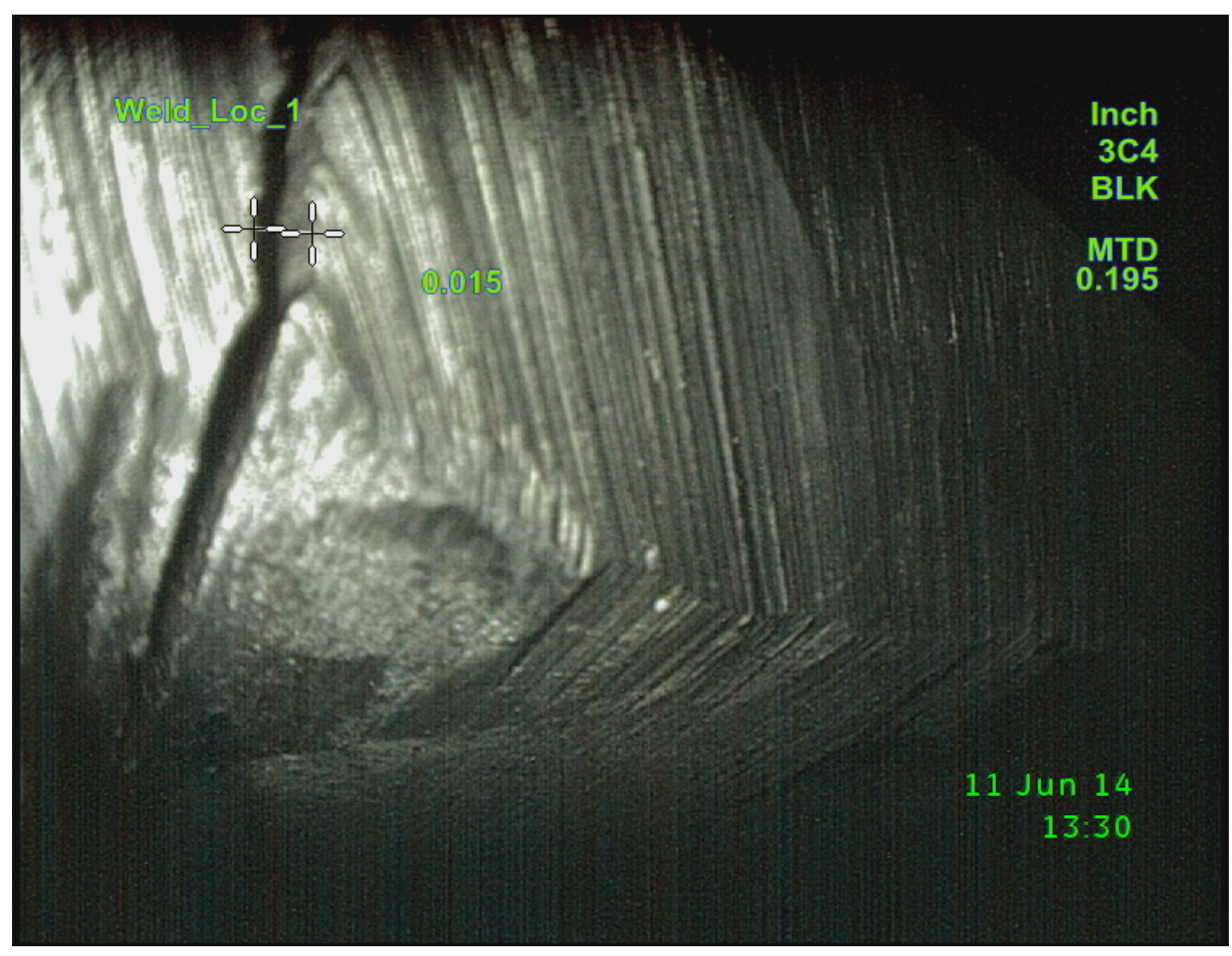

WELD LOC 1_01b 


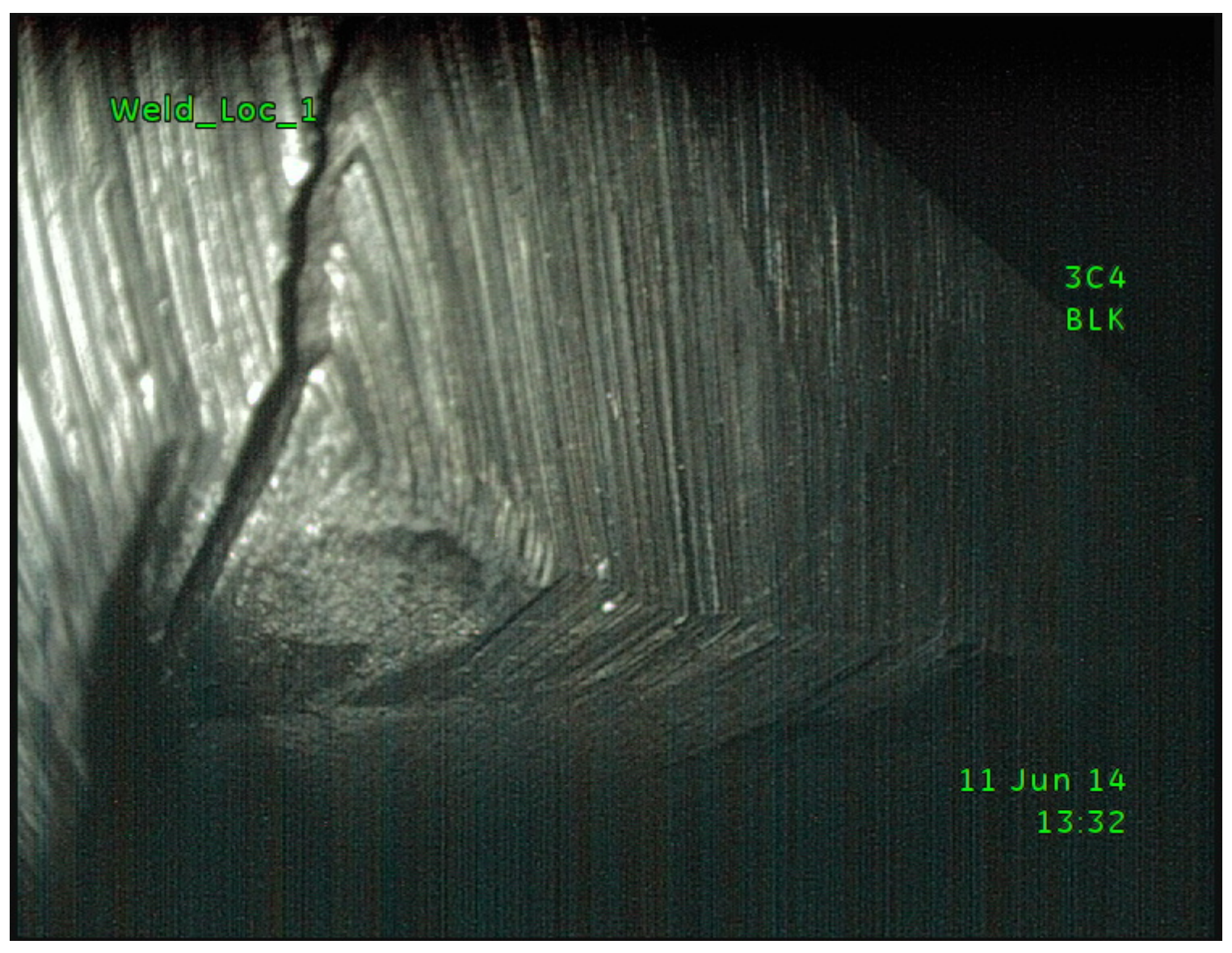

WELD LOC_1_02 


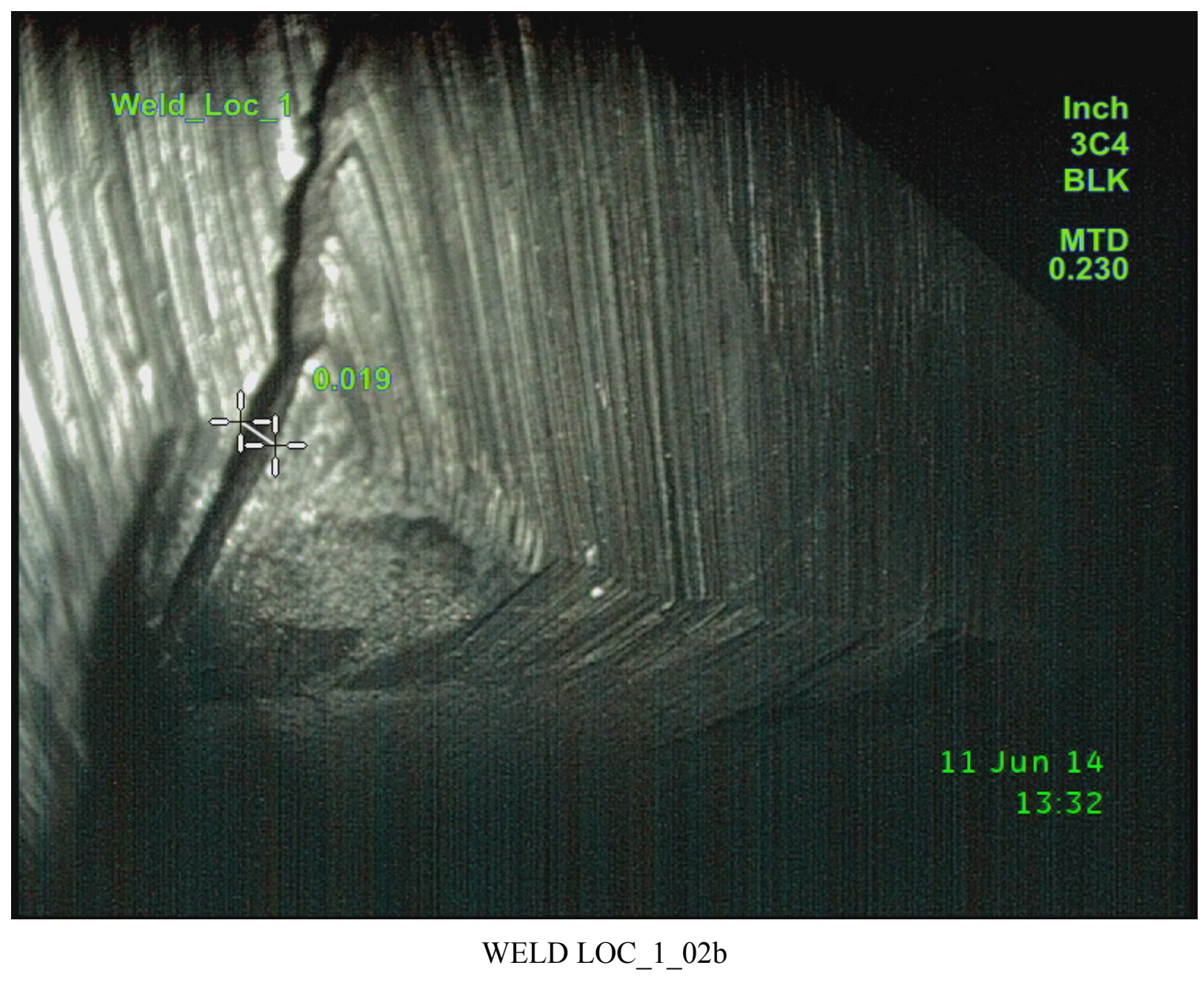




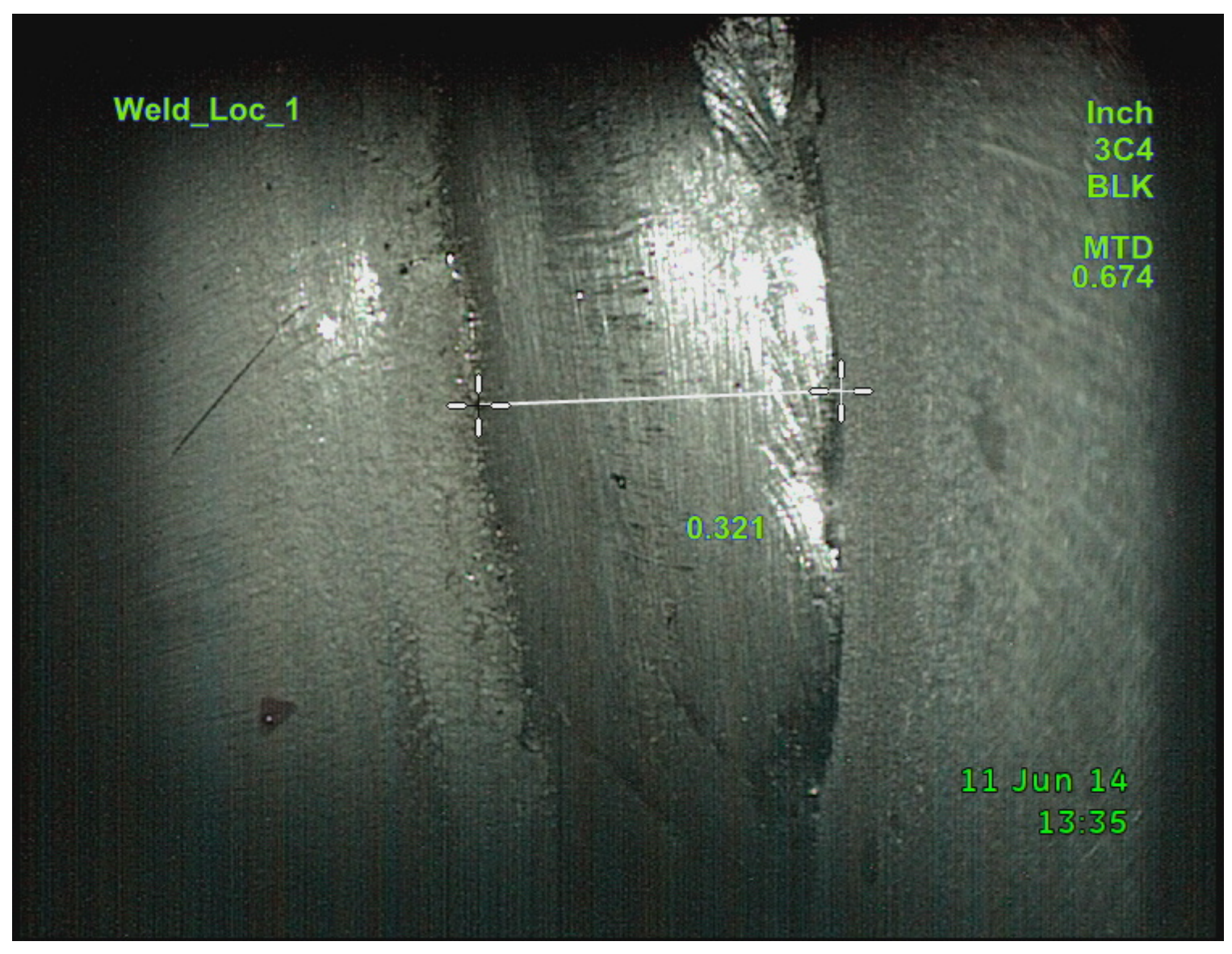

WELD LOC 1_03 


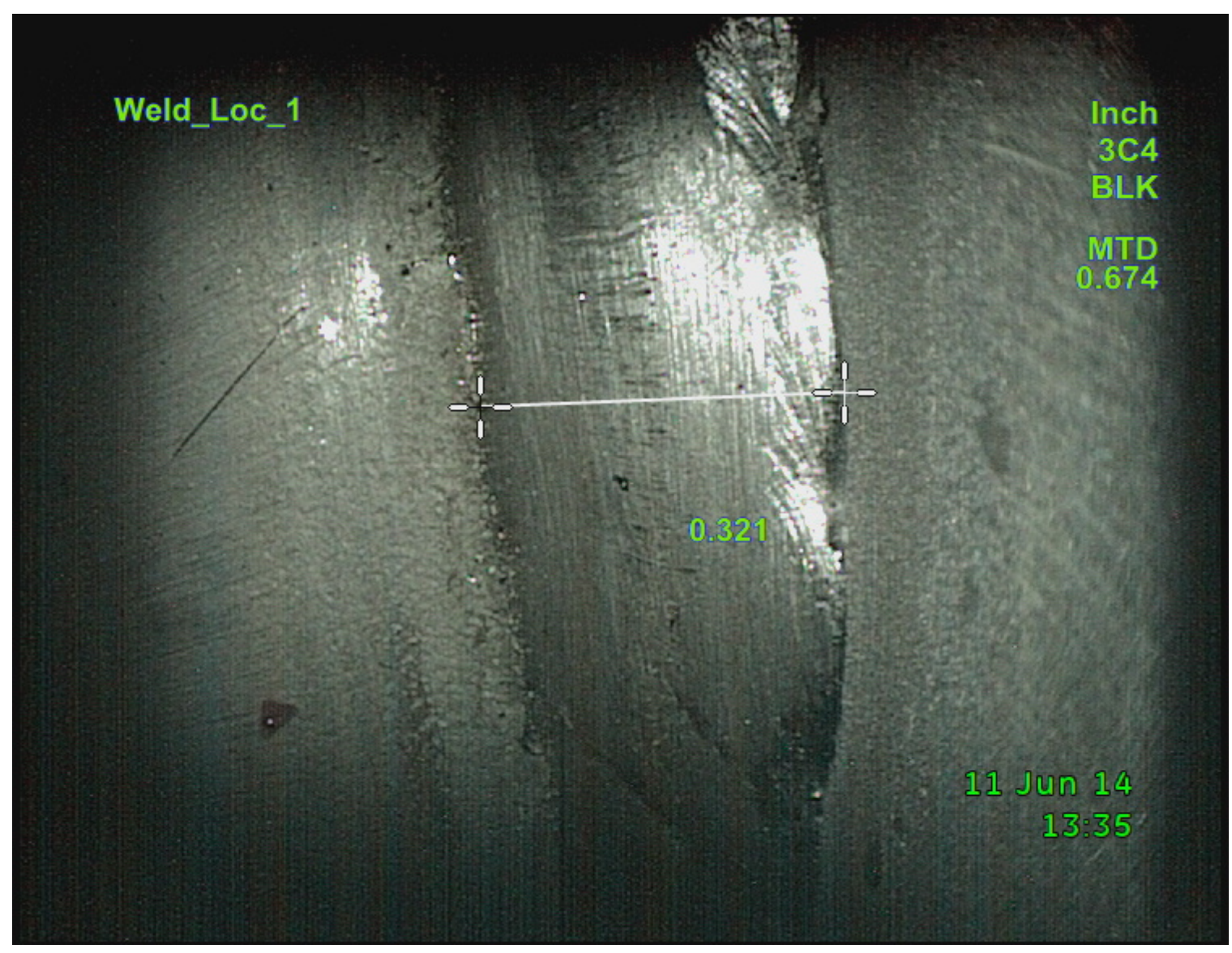

WELD LOC 1_03b 


\section{Appendix C TPR-7544 Sampling Procedure}


CPP-2707 CASK SURVEILLANCE AND SAMPLING

\begin{tabular}{|l|l|l|}
\hline INTEC & Technical Procedure & $\begin{array}{l}\text { For Additional Info: } \\
\text { http://EDMS }\end{array}$ \\
\hline
\end{tabular}

Manual: INTEC 749 Procedures

*The current revision can be verified on EDMS.
Identifier: TPR-7544

Revision*: 20

Page:

Cask Equipment ID \#

\section{INTRODUCTION}

\section{$1.1 \quad$ Purpose}

To ensure the environment in the casks at CPP-2707, surrounding the fuel, remains stable.

\subsection{Scope and Applicability}

The casks contain spent nuclear fuel from various sites. This procedure includes instructions for performing the required surveillances on the casks stored in the Dry Cask Storage Area (DCSA), CPP-2707. This includes checking pressures, checking for gas formation in the cask internal atmosphere, venting the casks, and backfilling the casks.

\section{PRECAUTIONS AND LIMITATIONS}

2.1 Weather conditions (sustained wind greater than $25 \mathrm{mph}$ for lifting activities, rain, lightning, and so forth) must be evaluated by supervision to determine whether or not procedure operations can continue or if a safe holding point needs to be identified and operations stopped at that point.

2.1.1 If operations must be halted, and normal configuration is desired, personnel may perform applicable steps of this procedure as directed by supervision.

2.2 Personnel must follow the applicable hazard mitigations detailed in Appendix B, Procedure Hazard Analysis.

2.3 If $110 \mathrm{~V}$ electrical power is needed a ground fault circuit interrupter (GFCI) must be used on $110 \mathrm{~V}$ equipment for personnel protection.

2.4 Aerial lifts must be operated in accordance with PRD-5107, "Aerial Lifts and Elevating Work Platforms."

2.5 Hard hats must be worn when working near (within $25 \mathrm{ft}$ ) an operating mobile crane or suspended load. Hard hats must be worn when working within the roped off area of an operating scissor lift or man lift.

2.6 Hoisting and rigging must be performed in compliance with requirements established in PRD-650, "ICP Hoisting and Rigging Requirements." 
2.7 Lifting or moving fuel-loaded casks on the CPP-2707 pad is NOT an activity that is authorized. (SAR-112)

2.8 Pressure regulator HCV-DSW-3-1 or -2 must be adjusted periodically to correct drift in gas pressure during operation, as required.

2.9 Radiological Control Technician coverage must be used when breaking open transfer lines, piping and any line suspected to be internally contaminated.

\section{PREREQUISITES}

\subsection{Planning and Coordination}

3.1.1 Ensure arrangements have been made for personnel to be notified by cell phone or other communication device of any voice page announcements or alerts when in any areas without voice paging or telephone service.

3.1.2 Supervision: Ensure appropriate personnel coverage as needed:
A. A minimum of at least one Certified Fuel Handler (CFH) (TSR-112)
B. A minimum of one radiological control technician (RCT)
C. Equipment Operators (EO) - one being a Qualified Crane Operator (if using a crane) (TSR-112)
D. Safeguard and Security (SG) for tamper-indicating device (TID)
E. Aerial lift operator
F. Instrument Technician (IT) or Electrician (EL) for monitoring equipment (pressure or temperature wiring)
G. System Engineer or designated alternate as required for performing corrosion inspections.

\subsection{Performance Documents}

3.2.1 Ensure a pre-job briefing has been performed per MCP-3003, "Performing Pre-Job Briefing and Documenting Feedback."
3.2.1.1 IF a formal pre-job briefing has been performed, THEN ensure Form 434.14, "Pre-Job Briefing Checklist," has been completed.

3.2.2 Ensure an approved ICP Radiological Work Permit is in place, if needed. 


\subsection{Special Tools, Equipment, Parts, and Supplies}

3.3.1 Ensure the following equipment and tools are available and staged, as required:

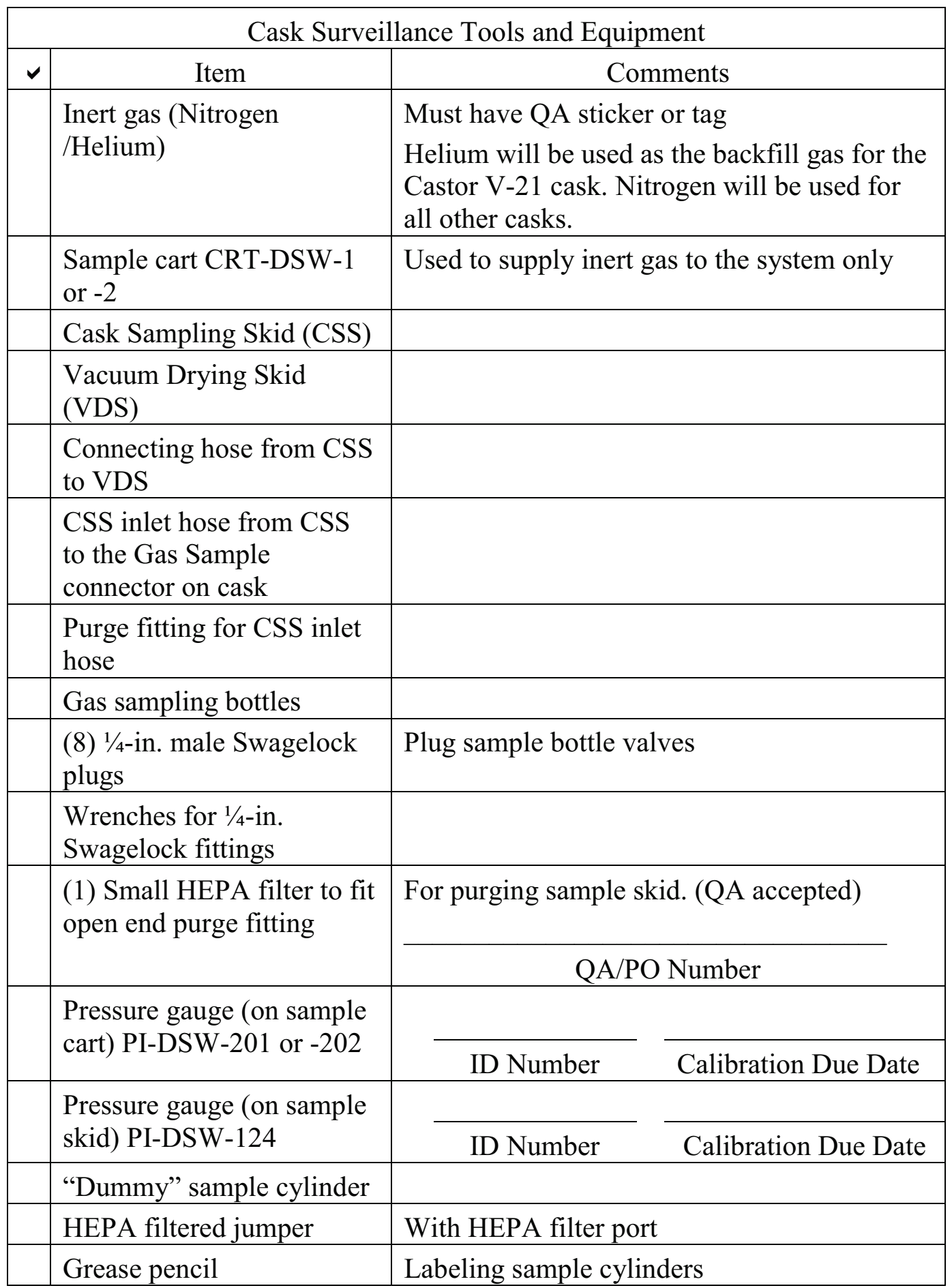




\section{CPP-2707 CASK SURVEILLANCE AND SAMPLING}

Identifier: TPR-7544

Revision*: 20

Page: $\quad 4$ of 48

\begin{tabular}{|l|l|l|}
\hline \multicolumn{2}{|c|}{ Cask Surveillance Tools and Equipment } \\
\hline$\checkmark$ & \multicolumn{1}{|c|}{$\begin{array}{c}\text { Comments } \\
\text { equivalent }\end{array}$} & \\
\hline & Nitrile gloves & For applying lubricant \\
\hline & Safety glasses/goggles & For applying lubricant \\
\hline & Wire or plastic ties & For attaching sample bottle labels \\
\hline & Generator (large) & $110 / 480$ volts, GFCI protected \\
\hline & Fall protection & Boom lift use \\
\hline & Mobile crane & For removing weather cover \\
\hline & Rigging equipment & For removing weather cover(s) \\
\hline & Torque wrench(s) & $\begin{array}{l}\text { VSC-17 cask weather cover bolts. Capable of } \\
\text { torquing } 75 \mathrm{ft} \bullet 1 \mathrm{~b}, 100 \mathrm{ft} \bullet 1 \mathrm{~b} \text { and } 150 \mathrm{ft} \bullet 1 \mathrm{~b}\end{array}$ \\
\hline & $2-3 / 16$ in. Socket & VSC-17 cask weather cover bolts \\
\hline
\end{tabular}

\subsection{Training}

\subsubsection{Ensure training requirements of Appendix B are met.}

\section{INSTRUCTIONS}

4.1 Ensure Section 3, Prerequisites has been completed.

NOTE 1: Steps 4.6.4 through 4.6.5 or 4.7.4 through 4.7 .5 may be performed at any time as directed by supervision to allow for the 30 minute warm up time on the vacuum pump.

NOTE 2: $\quad$ The pressure gauge PI-DSW-124 is turned on for all pressure measuring activities. The pressure gauge will time-out and shut-off after extended periods of time and may be turned back on as needed.

4.2 IF the need exists to perform any task in the following routing table, GO TO and complete the appropriate section for that task; THEN RETURN TO this section to select another task.

\begin{tabular}{|l|l|}
\hline \multicolumn{1}{|c|}{ Task } & \multicolumn{1}{|c|}{ Procedure Section } \\
\hline Perform purge of cask sampling skid & Perform Section 4.3. \\
\hline Remove weather cover from cask & Perform Section 4.4. \\
\hline Remove port cover and obtain internal cask pressure & Perform Section 4.5. \\
\hline Obtain "blank" sample & Perform Section 4.6. \\
\hline
\end{tabular}


CPP-2707 CASK SURVEILLANCE AND SAMPLING

Identifier: TPR-7544

Revision*: 20

Page:

5 of 48

\begin{tabular}{|l|l|}
\hline \multicolumn{1}{|c|}{ Task } & \multicolumn{1}{|c|}{ Procedure Section } \\
\hline Sample cask atmosphere & Perform Section 4.7. \\
\hline Vent the cask & Perform Section 4.8. \\
\hline Backfill cask with inert gas & Perform Section 4.9. \\
\hline Reinstall port cover & Perform Section 4.10. \\
\hline Install the weather cover on cask & Perform Section 4.11. \\
\hline Perform post performance activities & Perform Section 4.12. \\
\hline
\end{tabular}

\subsection{Performing Purge of Cask Sampling Skid}

NOTE: The designation “- $X$ ”" is used to allow the component to be from sample cart CRT-DSW-1 or -2.

4.3.1 Ensure the following are connected, per Appendix A, Figure 1, with the CSS inlet hose downwind of the work area.
A. Inert gas bottle to sample cart CRT-DSW-X
B. Sample cart CRT-DSW-X to Cask Sampling Skid (CSS)
C. CSS to Vacuum Drying System (VDS)
D. CSS inlet hose to CSS
E. Purge fitting with HEPA filter to end of CSS inlet hose.

4.3.2 Ensure the following valves are closed:

\begin{tabular}{|l|l|l|l|}
\hline$\checkmark$ & $\checkmark$ & $\checkmark$ & \\
\hline & & & HCV-DSW-3-X (turn counter-clockwise to close) \\
\hline & & & NHV-DSW-2-X \\
\hline & & & NHV-DSW-1-X (on the sample cart) \\
\hline
\end{tabular}

4.3.3 Ensure inert gas bottle contains a minimum 200 psig.

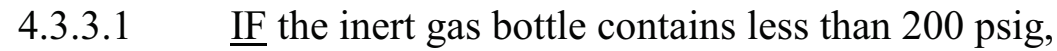
THEN change out the inert gas bottle and repeat Steps 4.3.1 through 4.3.3.

4.3.4 Ensure that the inert gas bottle has a quality acceptance label attached.

4.3.5 $\underline{\mathrm{RCT}}: \underline{\mathrm{IF}}$ a sample cylinder or HEPA filtered jumper is installed on the CSS,

THEN monitor the removal of the sample cylinder. 
Identifier: TPR-7544

Revision*: 20

Page:

6 of 48

4.3.6 Ensure a "Dummy" sample cylinder (with the inlet and outlet valves closed) is installed between the sample stub tubes, at valves VAV-DSW-23 and VAV-DSW-27.

4.3.7 Ensure the purge fitting with HEPA filter is installed on the end of the CSS inlet hose.

4.3.8 Ensure the following valves on the CSS are closed:

\begin{tabular}{|c|c|c|c|}
\hline$\checkmark$ & $\checkmark$ & $\checkmark$ & Valve \\
\hline & & & VAV-DSW-21 \\
\hline & & & VAV-DSW-24 \\
\hline
\end{tabular}

4.3.9 Ensure VAV-DSW-22 valve handle is positioned to the inert gas supply label on the CSS.

4.3.10 Ensure the following valves on the CSS are open:

\begin{tabular}{|l|l|l|l|}
\hline$\checkmark$ & $\checkmark$ & $\checkmark$ & \multicolumn{1}{|c|}{ Valve } \\
\hline & & & VAV-DSW-20 \\
\hline & & & VAV-DSW-23 \\
\hline & & & VAV-DSW-27 \\
\hline & & & VAV-DSW-28 \\
\hline & & & VAV-DSW-29 \\
\hline & & & Dummy sample inlet valve \\
\hline & & & Dummy sample outlet valve \\
\hline
\end{tabular}

4.3.11 Open inlet shutoff valve NHV-DSW-1-X on the sample cart.

4.3.12 Ensure the inert gas bottle valve is fully open.

4.3.13 RCT: Monitor HEPA filter at the end of the CSS inlet hose.

4.3.14 Adjust inert gas regulator valve HCV-DSW-3-X (turn clockwise to open) until PI-DSW-201 or -202 indicates approximately 10 psig.

4.3.15 Purge line for approximately one minute.

4.3.16 Open valve VAV-DSW-24 on the CSS. 


\section{CPP-2707 CASK SURVEILLANCE AND SAMPLING}

Identifier: TPR-7544

Revision*: 20

Page:

4.3.17 Ensure the following valves on the CSS are closed:

\begin{tabular}{|c|c|c|c|}
\hline$\checkmark$ & $\checkmark$ & $\checkmark$ & Valve \\
\hline & & & VAV-DSW-23 \\
\hline & & & VAV-DSW-27 \\
\hline
\end{tabular}

4.3.18 Purge line for approximately one minute.

4.3.19 Close inert gas regulator valve HCV-DSW-3-X (turn counter-clockwise to close).

4.3.20 Close the inert gas bottle valve.

4.3.21 Ensure the following valves on the CSS are closed in listed order:

\begin{tabular}{|c|c|c|c|}
\hline$\checkmark$ & $\checkmark$ & $\checkmark$ & Valve \\
\hline & & & VAV-DSW-20 \\
\hline & & & VAV-DSW-24 \\
\hline
\end{tabular}

4.3.22 Open valve VAV-DSW-27 on the CSS.

4.3.23 Close the following valves on the CSS:

\begin{tabular}{|l|l|l|l|}
\hline$\checkmark$ & $\checkmark$ & $\checkmark$ & \multicolumn{1}{|c|}{ Valve } \\
\hline & & & VAV-DSW-27 \\
\hline & & & VAV-DSW-28 \\
\hline & & & VAV-DSW-29 \\
\hline & & & Dummy sample inlet valve \\
\hline & & & Dummy sample outlet valve \\
\hline
\end{tabular}

4.3.24 RCT: Monitor the activities for the remainder of this section.

4.3.25 Remove HEPA filter from purge fitting from the end of the CSS inlet hose.

4.3.26 IF directed by supervision, THEN change out the purge fitting HEPA filter as directed by RCT.

4.3.27 IF NOT proceeding to other cask activities, THEN return the equipment to the original configuration or as directed by supervision. 


\subsection{Removing Weather Cover from Cask}

4.4.1 SG: IF TID is installed on the weather cover, THEN remove the TID.

4.4.2 RCT: Monitor as the bolts or tie down equipment are being removed.

4.4.3 IF bolts or tie down equipment are installed on the weather cover, THEN remove the bolts or tie down equipment.

4.4.4 IT/EL: IF monitoring equipment (temperature or pressure wiring) is installed on the weather cover, THEN remove the monitoring equipment.

NOTE: Weather cover removal is an ordinary lift. The VSC-17 weather cover, COV-DSF-1, weighs 1,600 lb. The V-21 weather cover weighs $1,150 \mathrm{lb}$.

4.4.5 EO: Rig the weather cover.

4.4.6 RCT: Monitor the weather cover as it is being removed.

4.4.7 EO: Raise the weather cover and place per supervision direction.

4.4.8 IF the weather cover has a gasket

AND the gasket remains with the cask, THEN leave the gasket in place.

4.4.9 System Engineer or Designated Alternate: Perform a visual inspection of the top of the cask specifically looking for signs of corrosion degradation or moisture.

4.4.10 IF NOT proceeding to other cask activities, THEN return the equipment to the original configuration or as directed by supervision. 


\subsection{Removing Port Cover and Obtaining Internal Cask Pressure}

4.5.1 IF port cover is installed on the cask, THEN remove port cover.

4.5.1.1 $\quad \underline{\text { RCT: }}$ Perform contamination survey of newly exposed cask areas.

4.5.1.1.1 $\underline{\text { RCT: }} \underline{\text { IF }}$ survey results are greater than $1,000 \mathrm{dpm} / 100 \mathrm{~cm}^{2}$ beta-gamma AND contamination area is NOT already established, $\underline{\text { THEN }}$ establish a contamination area per the RWP.

\subsection{IF directed by RCT,}

THEN decon the newly exposed areas.

\subsubsection{Store cover and components.}

4.5.2 Ensure the following valves on the CSS are closed:

\begin{tabular}{|c|c|c|c|}
\hline$\checkmark$ & $\checkmark$ & $\checkmark$ & Valve \\
\hline & & & VAV-DSW-20 \\
\hline & & & VAV-DSW-21 \\
\hline & & & VAV-DSW-23 \\
\hline & & & VAV-DSW-24 \\
\hline & & & VAV-DSW-27 \\
\hline & & & VAV-DSW-28 \\
\hline & & & VAV-DSW-29 \\
\hline
\end{tabular}

4.5.3 IF pressure transducer is installed on the cask, THEN remove the pressure transducer.

4.5.4 Connect CSS inlet hose to the cask port connector.

4.5.5 Open valve VAV-DSW-29.

4.5.6 Ensure valve VAV-DSW-28 on the CSS is open.

4.5.7 Monitor PI-DSW-124.

4.5.8 Allow pressure on PI-DSW-124 to stabilize for a minimum of one minute. 


\section{CPP-2707 CASK SURVEILLANCE AND SAMPLING}

Identifier: TPR-7544

Revision*: 20

Page:

10 of 48

4.5.9 Record internal cask pressure on PI-DSW-124.

PI-DSW-124 psig

4.5.10 Close valve VAV-DSW-28 on the CSS.

4.5.11 IF directed by supervision,

THEN perform the following:

4.5.11.1 Close valve VAV-DSW-29.

4.5.11.2 Disconnect CSS inlet hose from the cask port connector.

4.5.11.3 Install cask pressure transducer.

4.5.12 $\underline{\mathrm{RCT}}$ : IF fittings will be disconnected on the equipment, THEN monitor the disconnecting of this equipment.

4.5.13 IF NOT proceeding to other cask activities, THEN return the equipment to the original configuration or as directed by supervision.

\subsection{Obtaining "Blank" Sample}

4.6.1 $\quad \underline{\mathrm{RCT}}$ : Monitor installation of sample bottle onto CSS stub tubes.

4.6.2 Ensure a sample bottle is installed (with valves closed) onto CSS stub tubes.

4.6.3 Ensure CSS and the VDS are connected per Appendix A, Figure 1, with VDS exhaust HEPA filter directed downwind of the work area.

4.6.4 Ensure the following valves on the VDS are closed:

\begin{tabular}{|c|c|c|c|}
\hline$\checkmark$ & $\checkmark$ & $\checkmark$ & Valve \\
\hline & & & $1-\mathrm{AV}-\mathrm{H}-0037$ \\
\hline & & & $1-\mathrm{AV}-\mathrm{GA}-0038$ \\
\hline & & & $1-\mathrm{AV}-\mathrm{H}-0039$ \\
\hline
\end{tabular}




\section{CPP-2707 CASK SURVEILLANCE AND SAMPLING}

Identifier: TPR-7544

Revision*: 20

Page:

NOTE: $\quad$ The vacuum pump 1-H-001 needs to warm up a minimum of 30 minutes.

4.6.5 IF vacuum pump 1-H-001 on the VDS is NOT already running, THEN perform the following:

4.6.5.1 Ensure the gas ballast valve on the vacuum pump is open (counter-clockwise to open).

4.6.5.2 Start vacuum pump 1-H-001 on the VDS.

Start time:

4.6.6 Ensure VAV-DSW-22 valve handle is positioned to the VDS label on the CSS.

4.6.7 Ensure the following valves on the CSS are closed:

\begin{tabular}{|c|c|c|c|}
\hline$\checkmark$ & $\checkmark$ & $\checkmark$ & Valve \\
\hline & & & VAV-DSW-20 \\
\hline & & & VAV-DSW-21 \\
\hline & & & VAV-DSW-28 \\
\hline
\end{tabular}

4.6.8 Ensure the following valves on CSS are open:

\begin{tabular}{|l|l|l|l|}
\hline$\checkmark$ & $\checkmark$ & $\checkmark$ & \multicolumn{1}{|c|}{ Valve } \\
\hline & & & VAV-DSW-23 \\
\hline & & & VAV-DSW-24 \\
\hline & & & Sample outlet valve \\
\hline & & & Sample inlet valve \\
\hline & & & VAV-DSW-27 \\
\hline
\end{tabular}

4.6.9 WHEN the vacuum pump has been running a minimum of 30 minutes, THEN close the gas ballast valve on the vacuum pump (clockwise). 


\section{CPP-2707 CASK SURVEILLANCE AND SAMPLING}

Identifier: TPR-7544

Revision*: 20

Page:

12 of 48

4.6.10 Ensure the following valves on the VDS are open:

\begin{tabular}{|c|c|c|c|}
\hline$\checkmark$ & $\checkmark$ & $\checkmark$ & Valve \\
\hline & & & $1-\mathrm{AV}-\mathrm{H}-0037$ \\
\hline & & & $1-\mathrm{AV}-\mathrm{GA}-0038$ \\
\hline
\end{tabular}

4.6.11 RCT: Monitor HEPA filters F-DSW-103 on the CSS and 1-AV-F-0040 on the VDS.

4.6.12 Open valve VAV-DSW-21 on CSS.

4.6.13 Monitor PI-DSW-124 on the CSS.

4.6.14 WHEN PI-DSW-124 on the CSS indicates a pressure of less than -11.5 psig,

THEN position the following valves as indicated:

\begin{tabular}{|l|l|l|l|l|}
\hline$\checkmark$ & $\checkmark$ & $\checkmark$ & \multicolumn{1}{|c|}{ VALVE } & \multicolumn{1}{|c|}{ POSITION } \\
\hline & & & VAV-DSW-21 on CSS & CLOSED \\
\hline & & & 1-AV-H-0037 on the VDS & CLOSED \\
\hline & & & Gas ballast valve on the VDS (CCW) & OPEN \\
\hline
\end{tabular}

4.6.15 Record pressure on PI-DSW-124 on CSS.

PI-DSW-124

psig

psig

psig

psig

4.6.16 Monitor PI-DSW-124 on the CSS for a minimum of 10 minutes.

Start time:

End time: 


\section{CPP-2707 CASK SURVEILLANCE AND SAMPLING}

4.6.17 Record pressure on PI-DSW-124 on CSS.

PI-DSW-124 psig psig psig psig

4.6.18 IF pressure changes more than $0.4 \mathrm{psig}$ AND this is the first time the pressure was NOT able to be maintained, THEN perform the following:

4.6.18.1 Ensure the following valves on the CSS are closed:

\begin{tabular}{|l|l|l|l|}
\hline$\checkmark$ & $\checkmark$ & $\checkmark$ & \multicolumn{1}{|c|}{ VALVE } \\
\hline & & & VAV-DSW-23 \\
\hline & & & VAV-DSW-27 \\
\hline & & & Sample outlet valve \\
\hline & & & Sample inlet valve \\
\hline
\end{tabular}

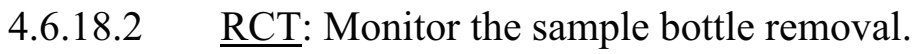

4.6.18.3 Remove the sample bottle from the CSS.

4.6.18.4 Repeat Steps 4.6.1 through 4.6.18.

4.6.19 IF the pressure changes more than 0.4 psig for a second time, THEN STOP operations and notify facility engineer and fuel handling supervision.

4.6.20 Ensure the following valves on the VDS are closed:

\begin{tabular}{|l|l|l|c|}
\hline$\checkmark$ & $\checkmark$ & $\checkmark$ & VALVE \\
\hline & & & $1-\mathrm{AV}-\mathrm{H}-0037$ \\
\hline & & & $1-\mathrm{AV}-\mathrm{GA}-0038$ \\
\hline & & & $1-\mathrm{AV}-\mathrm{H}-0039$ \\
\hline
\end{tabular}




\section{CPP-2707 CASK SURVEILLANCE AND SAMPLING}

Identifier: TPR-7544

Revision*: 20

Page:

4.6.21 Ensure the following valves on the CSS are closed:

\begin{tabular}{|l|l|l|l|}
\hline$\checkmark$ & $\checkmark$ & $\checkmark$ & \multicolumn{1}{|c|}{ VALVE } \\
\hline & & & VAV-DSW-20 \\
\hline & & & VAV-DSW-21 \\
\hline & & & VAV-DSW-23 \\
\hline & & & VAV-DSW-24 \\
\hline & & & VAV-DSW-27 \\
\hline & & & VAV-DSW-28 \\
\hline & & & Sample outlet valve \\
\hline & & & Sample inlet valve \\
\hline
\end{tabular}

4.6.22 Ensure inert gas bottle, sample cart CRT-DSW-X, CSS, and the VDS are connected per Appendix A, Figure 1, with the VDS HEPA filtered exhaust downwind of the work area.

NOTE: The designation "- $X$ ” is used to allow the component to be from sample cart CRT-DSW-1 or -2 .

4.6.23 Ensure the following valves are closed:

\begin{tabular}{|l|l|l|l|}
\hline$\checkmark$ & $\checkmark$ & $\checkmark$ & \\
\hline & & & HCV-DSW-3-X (turn counter-clockwise to close) \\
\hline & & & NHV-DSW-2-X \\
\hline & & & NHV-DSW-1-X (on the sample cart) \\
\hline
\end{tabular}

4.6.24 Ensure inert gas bottle contains a minimum 200 psig.

4.6.24.1 IF the inert gas bottle contains less than 200 psig, THEN change out the inert gas bottle and repeat Steps 4.6.22 through 4.6.24.

4.6.25 Ensure that the inert gas bottle has a quality acceptance label attached.

4.6.26 Ensure the inlet shutoff valve NHV-DSW-1-X on the sample cart is open.

4.6.27 Ensure VAV-DSW-22 valve handle is positioned to the inert gas supply label on the CSS. 


\section{CPP-2707 CASK SURVEILLANCE AND SAMPLING}

Identifier: TPR-7544

Revision*: 20

Page:

4.6.28 Ensure the inert gas bottle valve is fully open.

4.6.29 Ensure the following valves are open on the CSS:

\begin{tabular}{|l|l|l|l|}
\hline$\checkmark$ & $\checkmark$ & $\checkmark$ & \multicolumn{1}{|c|}{ VALVE } \\
\hline & & & VAV-DSW-20 \\
\hline & & & VAV-DSW-23 \\
\hline & & & VAV-DSW-27 \\
\hline & & & Sample Inlet valve \\
\hline & & & Sample Outlet valve \\
\hline
\end{tabular}

NOTE: If inert gas regulator valve $H C V$ - $D S W-3-X$ is opened too quickly, the system will overpressure outside the desired range.

4.6.30 Very slowly open inert gas regulator valve HCV-DSW-3-X (turn clockwise to open), avoiding overpressurization, until PI-DSW-124 on the CSS indicates approximately 0 psig, then close valve NHV-DSW-1-X on the sample cart.

4.6.31 Close the inert gas regulator valve HCV-DSW-3-X (counter-clockwise to close).

4.6.32 Close the gas ballast valve on the vacuum pump (clockwise).

4.6.33 Ensure VAV-DSW-22 valve handle is positioned to the VDS label on the CSS.

4.6.34 Ensure the following valves on the VDS are open:

\begin{tabular}{|c|c|c|c|}
\hline$\checkmark$ & $\checkmark$ & $\checkmark$ & VALVE \\
\hline & & & $1-\mathrm{AV}-\mathrm{H}-0037$ \\
\hline & & & $1-\mathrm{AV}-\mathrm{GA}-0038$ \\
\hline
\end{tabular}

4.6.35 Open VAV-DSW-21 on the CSS.

4.6.36 Open NHV-DSW-1-X on the sample cart.

4.6.37 RCT: Monitor the outlet HEPA exhaust filter on the VDS. 
4.6.38 WHEN PI-DSW-124 on the CSS stabilizes on the maximum vacuum achievable AND indicates less than -11.5 psig, THEN close valve VAV-DSW-21 on the CSS.

4.6.39 Allow pressure on PI-DSW-124 on the CSS to stabilize for a minimum of one minute.

4.6.40 Record pressure indication on PI-DSW-124 on the CSS.

PI-DSW-124 psig PI-DSW-124 psig

4.6.41 Ensure VAV-DSW-22 valve handle is positioned to the inert gas supply label on the CSS.

4.6.42 Allow pressure on PI-DSW-124 on the CSS to stabilize for a minimum of one minute.

4.6.42.1 Record pressure indication on PI-DSW-124 on the CSS.

$$
\begin{array}{lr}
\text { PI-DSW-124 } & \text { psig } \\
\text { PI-DSW-124 } & \text { psig }
\end{array}
$$

4.6.43 Open the gas ballast valve on the vacuum pump 1-H-001 on the VDS (counter-clockwise to open).

NOTE: If inert gas regulator valve $H C V$-DSW-3-X is opened too quickly the system will overpressure outside the desired range. To prevent this condition ensure that $H C V-D S W-3-X$ is opened very slowly until pressure increase rate is determined.

4.6.44 Slowly open the inert gas regulator valve HCV-DSW-3-X (turn clockwise to open) until PI-DSW-124 on the CSS indicates approximately $0 \mathrm{psig}$, then close the valve NHV-DSW-1-X on the sample cart.

4.6.44.1 IF HCV-DSW-3-X was opened too quickly and the system was over pressurized, THEN perform the following:

4.6.44.1.1 Slowly open bleed valve NHV-DSW-2-X until system pressure is normalized.

4.6.44.1.2 Repeat Step 4.6.44. 


\section{CPP-2707 CASK SURVEILLANCE AND SAMPLING}

Identifier: TPR-7544

Revision*: 20

Page:

17 of 48

4.6.45 Close the inert gas regulator valve HCV-DSW-3-X (counter-clockwise to close).

4.6.46 Close the inert gas bottle valve.

4.6.47 Allow pressure on PI-DSW-124 on the CSS to stabilize for a minimum of one minute.

4.6.47.1 Record pressure indication on PI-DSW-124 on the CSS.

$$
\begin{array}{lr}
\text { PI-DSW-124 } & \text { psig } \\
\cline { 2 - 2 } \text { PI-DSW-124 } & \text { psig }
\end{array}
$$

4.6.48 Ensure the following valves on the CSS are closed in the order listed:

\begin{tabular}{|l|l|l|l|}
\hline$\checkmark$ & $\checkmark$ & $\checkmark$ & \multicolumn{1}{|c|}{ VALVE } \\
\hline & & & Sample cylinder outlet valve \\
\hline & & & Sample cylinder inlet valve \\
\hline & & & VAV-DSW-23 \\
\hline & & & VAV-DSW-27 \\
\hline
\end{tabular}

4.6.49 $\underline{\text { IF }}$ directed by supervision

THEN shut down vacuum pump 1-H-001 on the VDS.

4.6.50 Ensure the following valves on the VDS are closed:

\begin{tabular}{|l|l|l|c|}
\hline$\checkmark$ & $\checkmark$ & $\checkmark$ & VALVE \\
\hline & & & $1-\mathrm{AV}-\mathrm{H}-0037$ \\
\hline & & & $1-\mathrm{AV}-\mathrm{GA}-0038$ \\
\hline & & & $1-\mathrm{AV}-\mathrm{H}-0039$ \\
\hline
\end{tabular}

4.6.51 Ensure the following valves on the CSS are closed:

\begin{tabular}{|c|c|c|c|}
\hline$\checkmark$ & $\checkmark$ & $\checkmark$ & VALVE \\
\hline & & & VAV-DSW-20 \\
\hline & & & VAV-DSW-21 \\
\hline & & & VAV-DSW-24 \\
\hline & & & VAV-DSW-28 \\
\hline
\end{tabular}


NOTE: $\quad$ Steps 4.6.52 through 4.6 .59 may be performed concurrently as directed by supervision.

4.6.52 RCT: Perform radiation survey on "blank" sample bottle.

4.6.52.1 RCT: IF survey results are greater than $100 \mathrm{mR} / \mathrm{hr}$ at $30 \mathrm{~cm}$, THEN perform the following.

4.6.52.1.1 STOP work and notify supervision and RadCon supervision for an evaluation.

4.6.52.1.2 DO NOT continue without RadCon supervision approval.

4.6.53 IF survey results are less than $100 \mathrm{mR} / \mathrm{hr}$ at $30 \mathrm{~cm}$, THEN remove sample bottle.

4.6.54 RCT: Perform contamination survey on "blank" sample bottle.

4.6.54.1 $\underline{\text { IF }}$ survey results are greater than $1,000 \mathrm{dpm} / 100 \mathrm{~cm}^{2}$ beta-gamma, THEN perform the following:

4.6.54.1.1 $\underline{\text { STOP }}$ work and notify supervision and RadCon supervision for an evaluation.

4.6.54.1.2 DO NOT continue without RadCon supervision approval.

4.6.55 Plug both "blank" sample bottle valves using Swagelock plugs.

4.6.56 RCT: Label "blank" sample bottle as having potential internal contamination.

4.6.57 Install $\underline{\mathrm{ONE}}$ of the following on the CSS as directed by supervision:
A. A "dummy" sample bottle
B. A HEPA filtered jumper
C. The caps
D. Another sample bottle. 
4.6.58 Fill out the provided sample bottle label using a grease pencil with the following information:
A. Operator
B. Date
C. Time
D. Cask \#
E. Sample \# "Blank Sample."

4.6.59 Attach the sample bottle label to the sample bottle.

4.6.60 Place "blank" sample bottle in a safe area to prevent damage to the sample bottle valves.

4.6.61 IF another "blank" sample is required to be taken, GO TO Step 4.6.1 WITHOUT RETURNING TO this step.

4.6.62 RCT: IF fittings will be disconnected on the equipment, THEN monitor the disconnecting of this equipment.

4.6.63 IF NOT proceeding to other cask activities, THEN return the equipment to the original configuration or as directed by supervision.

\subsection{Sampling Cask Atmosphere}

4.7.1 RCT: Monitor installation of sample bottle onto CSS stub tubes.

4.7.2 Ensure a sample bottle is installed (with valves closed) onto CSS stub tubes.

4.7.3 Ensure CSS and the VDS are connected per Appendix A, Figure 1, with VDS exhaust HEPA filter directed downwind of the work area.

4.7.4 Ensure the following valves on the VDS are closed:

\begin{tabular}{|c|c|c|c|}
\hline$\checkmark$ & $\checkmark$ & $\checkmark$ & Valve \\
\hline & & & $1-\mathrm{AV}-\mathrm{H}-0037$ \\
\hline & & & $1-\mathrm{AV}-\mathrm{GA}-0038$ \\
\hline & & & $1-\mathrm{AV}-\mathrm{H}-0039$ \\
\hline
\end{tabular}




\section{CPP-2707 CASK SURVEILLANCE AND SAMPLING}

Identifier: TPR-7544

Revision*: 20

Page:

NOTE: $\quad$ The vacuum pump 1-H-001 needs to warm up a minimum of 30 minutes.

4.7.5 IF vacuum pump 1-H-001 on the VDS is NOT already running, THEN perform the following:

4.7.5.1 Ensure the gas ballast valve on the vacuum pump is open (counter-clockwise to open).

4.7.5.2 Start vacuum pump 1-H-001 on the VDS.

Start time:

4.7.6 Ensure VAV-DSW-22 valve handle is positioned to the VDS label on the CSS.

4.7.7 Ensure the following valves on the CSS are closed:

\begin{tabular}{|c|c|c|c|}
\hline$\triangleleft$ & $\checkmark$ & $\checkmark$ & Valve \\
\hline & & & VAV-DSW-20 \\
\hline & & & VAV-DSW-21 \\
\hline & & & VAV-DSW-28 \\
\hline
\end{tabular}

4.7.8 Ensure the following valves on CSS are open:

\begin{tabular}{|l|l|l|l|}
\hline$\checkmark$ & $\checkmark$ & $\checkmark$ & \multicolumn{1}{|c|}{ Valve } \\
\hline & & & VAV-DSW-23 \\
\hline & & & VAV-DSW-24 \\
\hline & & & Sample outlet valve \\
\hline & & & Sample inlet valve \\
\hline & & & VAV-DSW-27 \\
\hline
\end{tabular}

4.7.9 WHEN the vacuum pump has been running a minimum of 30 minutes, THEN close the gas ballast valve on the vacuum pump (clockwise). 


\section{CPP-2707 CASK SURVEILLANCE AND SAMPLING}

Identifier: TPR-7544

Revision*: 20

Page:

4.7.10 Ensure the following valves on the VDS are open:

\begin{tabular}{|c|c|c|c|}
\hline$\checkmark$ & $\checkmark$ & $\checkmark$ & Valve \\
\hline & & & $1-\mathrm{AV}-\mathrm{H}-0037$ \\
\hline & & & $1-\mathrm{AV}-\mathrm{GA}-0038$ \\
\hline
\end{tabular}

4.7.11 RCT: Monitor HEPA filters F-DSW-103 on the CSS and 1-AV-F-0040 on the VDS.

4.7.12 Open valve VAV-DSW-21 on CSS.

4.7.13 Monitor PI-DSW-124 on the CSS.

4.7.14 WHEN PI-DSW-124 on the CSS indicates a pressure of less than -11.5 psig,

THEN position the following valves as indicated:

\begin{tabular}{|l|l|l|l|l|}
\hline$\checkmark$ & $\checkmark$ & $\checkmark$ & \multicolumn{1}{|c|}{ VALVE } & \multicolumn{1}{|c|}{ POSITION } \\
\hline & & & VAV-DSW-21 on CSS & CLOSED \\
\hline & & & 1-AV-H-0037 on the VDS & CLOSED \\
\hline & & & Gas ballast valve on the VDS (CCW) & OPEN \\
\hline
\end{tabular}

4.7.15 Record pressure on PI-DSW-124 on CSS.

PI-DSW-124 psig psig psig psig

4.7.16 Monitor PI-DSW-124 on the CSS for a minimum of 10 minutes.

Start time: End time: 


\section{CPP-2707 CASK SURVEILLANCE AND SAMPLING}

4.7.17 Record pressure on PI-DSW-124 on CSS.

PI-DSW-124 psig psig psig psig

4.7.18 IF pressure changes more than 0.4 psig AND this is the first time the pressure was NOT able to be maintained, THEN perform the following.

4.7.18.1 Ensure the following valves on the CSS are closed:

\begin{tabular}{|c|c|c|c|}
\hline$\checkmark$ & $\checkmark$ & $\checkmark$ & \multicolumn{1}{|c|}{ VALVE } \\
\hline & & & VAV-DSW-23 \\
\hline & & & VAV-DSW-27 \\
\hline & & & Sample outlet valve \\
\hline & & & Sample inlet valve \\
\hline
\end{tabular}

4.7.18.2 $\underline{\mathrm{RCT}}$ : Monitor the sample bottle removal.

4.7.18.3 Remove the sample bottle from the CSS.

4.7.18.4 Repeat Steps 4.7.1 through 4.7.18.

4.7.19 IF the pressure changes more than 0.4 psig for a second time, $\underline{\text { THEN }}$ STOP operations and notify facility engineer and fuel handling supervision.

4.7.20 Ensure the following valves on the VDS are closed:

\begin{tabular}{|c|c|c|c|}
\hline$\checkmark$ & $\checkmark$ & $\checkmark$ & VALVE \\
\hline & & & $1-\mathrm{AV}-\mathrm{H}-0037$ \\
\hline & & & $1-\mathrm{AV}-\mathrm{GA}-0038$ \\
\hline & & & $1-\mathrm{AV}-\mathrm{H}-0039$ \\
\hline
\end{tabular}




\section{CPP-2707 CASK SURVEILLANCE AND SAMPLING}

Identifier: TPR-7544

Revision*: 20

Page:

23 of 48

4.7.21 Ensure the following valves on the CSS are closed:

\begin{tabular}{|l|l|l|l|}
\hline$\checkmark$ & $\checkmark$ & $\checkmark$ & \multicolumn{1}{|c|}{ VALVE } \\
\hline & & & VAV-DSW-20 \\
\hline & & & VAV-DSW-21 \\
\hline & & & VAV-DSW-23 \\
\hline & & & VAV-DSW-24 \\
\hline & & & VAV-DSW-27 \\
\hline & & & VAV-DSW-28 \\
\hline & & & Sample outlet valve \\
\hline & & & Sample inlet valve \\
\hline
\end{tabular}

4.7.22 IF port cover is installed on the cask, THEN remove port cover.

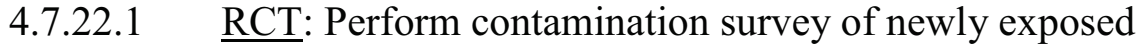
areas.

4.7.22.1.1 RCT: IF survey results are greater than $1,000 \mathrm{dpm} / 100 \mathrm{~cm}^{2}$ beta-gamma $\underline{\text { AND }}$ contamination area is NOT already established,

$\underline{\text { THEN }}$ establish a contamination area per the RWP.

\subsection{IF directed by RCT, THEN decon as directed by RCT and supervision.}

4.7.22.2 Store cover and components.

4.7.23 IF pressure transducer is installed on the cask, THEN remove the pressure transducer.

4.7.24 Ensure the CSS inlet hose is connected to the cask port connector.

4.7.25 Ensure valve VAV-DSW-29 is open.

4.7.26 Ensure VAV-DSW-22 valve handle is positioned to the VDS label on the CSS. 


\section{CPP-2707 CASK SURVEILLANCE AND SAMPLING}

Identifier: TPR-7544

Revision*: 20

Page:

4.7.27 Ensure the following valves on CSS are open:

\begin{tabular}{|l|l|l|l|}
\hline$\checkmark$ & $\checkmark$ & $\checkmark$ & \multicolumn{1}{|c|}{ VALVE } \\
\hline & & & VAV-DSW-23 \\
\hline & & & Sample cylinder inlet valve \\
\hline & & & Sample cylinder outlet valve \\
\hline & & & VAV-DSW-27 \\
\hline
\end{tabular}

4.7.28 Close the gas ballast valve on the vacuum pump (clockwise).

4.7.29 Ensure the following valves on the VDS are open:

\begin{tabular}{|c|c|c|c|}
\hline$\checkmark$ & $\checkmark$ & $\checkmark$ & VALVE \\
\hline & & & $1-\mathrm{AV}-\mathrm{H}-0037$ \\
\hline & & & $1-\mathrm{AV}-\mathrm{GA}-0038$ \\
\hline
\end{tabular}

4.7.30 RCT: Monitor HEPA filters F-DSW-103 on the CSS and the outlet HEPA filter on the VDS during sampling activities.

4.7.31 Open valves VAV-DSW-28 and VAV-DSW-21 on the CSS.

4.7.32 IF a rise in radiation is detected, THEN close VAV-DSW-21 on CSS and 1-AV-H-0037 on the VDS.

NOTE: If the radiation level rises due to noble gases, the radiation level will dissipate after valves $V A V-D S W-21$ on the CSS and 1-AV-H-0037 on the VDS are CLOSED. It may take as long as 15 to 20 minutes for the radiation level to dissipate. If the radiation level rises due to particulate contamination, the radiation level will remain elevated after the inert gas supply is shut off.

4.7.32.1 IF the source of the radiation is determined to be particulate, THEN perform the following:

4.7.32.1.1 STOP the operation in progress.

4.7.32.1.2 Notify the system engineer or the facility manager.

4.7.32.2 IF the source of the radiation is determined to be a gas, $\underline{\text { THEN }}$ ensure the following:

\subsection{Valve VAV-DSW-21 on the CSS and 1-AV-H-0037 on the VDS are open.}


4.7.32.2.2 The exhaust of vacuum pump 1-H-001 on the VDS is downwind of the work area.

4.7.33 Record pressure from PI-DSW-124 on the CSS.

Pressure:

Pressure:

NOTE: $\quad$ To make sure a proper sample is taken in the following steps it is necessary to ensure a vacuum of at least -1 psi has been achieved from the starting value recorded in Step 4.7.33.

4.7.34 Allow vacuum indicated on PI-DSW-124 to decrease by -1 psi as indicated on PI-DSW-124 and record the value below.

Pressure:

Pressure:

4.7.35 Close valve VAV-DSW-21 on the CSS.

4.7.36 Ensure the following valves are closed in the listed order on the CSS:

\begin{tabular}{|c|c|c|l|}
\hline$\bullet$ & $\bullet$ & $\checkmark$ & \multicolumn{1}{|c|}{ VALVE } \\
\hline & & & Sample cylinder outlet valve \\
\hline & & & Sample cylinder inlet valve \\
\hline & & & VAV-DSW-23 \\
\hline & & & VAV-DSW-27 \\
\hline
\end{tabular}

4.7.37 Ensure the following valves are closed on the VDS:

\begin{tabular}{|c|c|c|c|}
\hline$\vee$ & $\checkmark$ & $\checkmark$ & VALVE \\
\hline & & & $1-\mathrm{AV}-\mathrm{H}-0037$ \\
\hline & & & $1-\mathrm{AV}-\mathrm{GA}-0038$ \\
\hline
\end{tabular}

4.7.38 Open gas ballast valve on the vacuum pump 1-H-001 on the VDS (counter-clockwise to open).

4.7.39 Allow pressure on PI-DSW-124 on the CSS to stabilize for a minimum of one minute. 
4.7.40 Record pressure indication on PI-DSW-124 on the CSS.

PI-DSW-124 psig

PI-DSW-124 psig

4.7.41 Close valve VAV-DSW-28 on the CSS.

4.7.42 IF sampling is completed for the shift

OR directed by supervision to shut down the vacuum pump, THEN perform the following:

4.7.42.1 Ensure the gas ballast valve on the vacuum pump 1-H-001 on the VDS is open (counter-clockwise to open).

4.7.42.2 Shut down vacuum pump 1-H-001 on the VDS.

4.7.43 Ensure the following valves on the VDS are closed:

\begin{tabular}{|c|c|c|c|}
\hline$\checkmark$ & $\checkmark$ & $\checkmark$ & VALVE \\
\hline & & & $1-\mathrm{AV}-\mathrm{H}-0037$ \\
\hline & & & $1-\mathrm{AV}-\mathrm{GA}-0038$ \\
\hline & & & $1-\mathrm{AV}-\mathrm{H}-0039$ \\
\hline
\end{tabular}

NOTE: $\quad$ Steps 4.7.44 through 4.7.51 may be performed concurrently as directed by supervision.

4.7.44 $\underline{\text { RCT: }}$ Perform radiation survey on sample bottle.

4.7.44.1 IF survey results are greater than $100 \mathrm{mR} / \mathrm{hr}$ at contact, THEN perform the following:

4.7.44.1.1 $\quad$ STOP work and notify supervision and RadCon supervision for an evaluation. 4.7.44.1.2 $\frac{\text { DO NOT }}{\text { approval. }}$ continue without RadCon supervision

4.7.45 IF survey results are less than $100 \mathrm{mR} / \mathrm{hr}$ at contact, THEN remove sample bottle. 
4.7.46 RCT: Perform contamination survey on sample bottle.

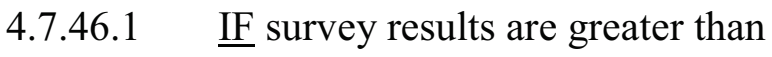
$1,000 \mathrm{dpm} / 100 \mathrm{~cm}^{2}$ beta-gamma, THEN perform the following:

4.7.46.1.1 $\quad$ STOP work and notify supervision and RadCon supervision for an evaluation.

4.7.46.1.2 DO NOT continue without RadCon supervision approval.

4.7.47 Plug both sample bottle valves using Swagelock plugs.

4.7.48 Install $\mathrm{ONE}$ of the following on the CSS as directed by supervision:
A. A "dummy" sample bottle
B. A HEPA filtered jumper
C. The caps
D. Another sample bottle.

4.7.49 RCT: Label sample bottle as having potential internal contamination.

4.7.50 Fill out the provided sample bottle label using a grease pencil with the following information:
A. Operator
B. Date
C. Time
D. Cask \#
E. Sample \#.

4.7.51 Attach the sample bottle label to the sample bottle.

4.7.52 Place sample bottle in a safe area to prevent damage to the sample bottle valves.

4.7.53 IF another sample is required to be taken,

GO TO Step 4.7.1

WITHOUT RETURNING TO this step. 
4.7.54 Record time and date the cask sampling activities are completed.

$$
\text { Time Date }
$$

4.7.55 RCT: Perform final contamination survey on all equipment and cask sample area.

4.7.56 IF survey results are greater than $1,000 \mathrm{dpm} / 100 \mathrm{~cm}^{2}$ beta-gamma, THEN perform the following:

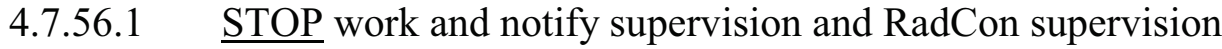
for an evaluation.

4.7.56.2 DO NOT continue without RadCon supervision approval.

4.7.57 Close valve VAV-DSW-29.

4.7.58 RCT: Monitor the disconnecting of this equipment.

4.7.59 Disconnect CSS inlet hose from cask port connector.

4.7.60 Install cask pressure transducer.

4.7.61 RCT: IF fittings will be disconnected on the equipment, THEN monitor the disconnecting of this equipment.

4.7.62 IF NOT proceeding to other cask activities, THEN return the equipment to the original configuration or as directed by supervision.

\subsection{Venting the Cask}

4.8.1 Ensure the following valves on the CSS are closed:

\begin{tabular}{|c|c|c|c|}
\hline$\checkmark$ & $\checkmark$ & $\checkmark$ & VALVE \\
\hline & & & VAV-DSW-20 \\
\hline & & & VAV-DSW-21 \\
\hline & & & VAV-DSW-23 \\
\hline & & & VAV-DSW-24 \\
\hline & & & VAV-DSW-27 \\
\hline & & & VAV-DSW-28 \\
\hline & & & VAV-DSW-29 \\
\hline
\end{tabular}


4.8.2 IF the HEPA filtered jumper will be installed, THEN perform the following:

4.8.2.1 Request RCT to monitor the installation of the jumper.

4.8.2.2 Ensure HEPA filtered jumper is installed on the CSS and workers remain upwind.

4.8.3 IF port cover is installed on the cask, THEN remove port cover.

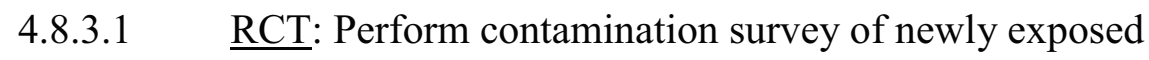
areas.

4.8.3.1.1 RCT: IF survey results are greater than $1,000 \mathrm{dpm} / 100 \mathrm{~cm}^{2}$ beta-gamma

AND contamination area is NOT already established, THEN establish a contamination area per the RWP.

\subsection{IF directed by RCT, THEN decon as directed by RCT and supervision.}

4.8.3.2 Store cover and components.

4.8.4 IF pressure transducer is installed on the cask, THEN remove the pressure transducer.

4.8.5 Ensure the CSS inlet hose is connected to the cask port connector.

4.8.6 Ensure valve VAV-DSW-29 is open.

4.8.7 RCT: Monitor HEPA filters F-DSW-103 and HEPA filter on the jumper on the CSS during venting activities.

4.8.8 Open the following valves on the CSS in the order listed:

\begin{tabular}{|c|c|c|c|}
\hline$v$ & $v$ & $v$ & VALVE \\
\hline & & & VAV-DSW-27 \\
\hline & & & VAV-DSW-28 \\
\hline
\end{tabular}


4.8.9 IF a rise in radiation is detected,

THEN close VAV-DSW-28 on CSS.

NOTE: If the radiation level rises due to noble gases, the radiation level will dissipate after VAV-DSW-28 on the CSS is CLOSED. It may take as long as 15 to 20 minutes for the radiation level to dissipate. If the radiation level rises due to particulate contamination, the radiation level will remain elevated after the inert gas supply is shut off.

4.8.9.1 IF the source of the radiation is determined to be particulate, THEN $\underline{\text { STOP }}$ the operation in progress and notify the system engineer or the facility manager.

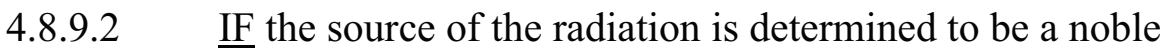
gas, THEN ensure the following:

\subsection{Valve VAV-DSW-28 on the CSS is open.}

4.8.9.2.2 The workers remain upwind of the exhaust from the HEPA on the jumper on the CSS.

4.8.10 Monitor PI-DSW-124 on the CSS.

4.8.11 WHEN PI-DSW-124 on the CSS indicates approximately 0 psig and NO airflow is audible through the HEPA filter, THEN CLOSE the following valves in the listed order on the CSS:

\begin{tabular}{|c|c|c|c|}
\hline$\checkmark$ & $\checkmark$ & $\checkmark$ & VALVE \\
\hline & & & VAV-DSW-28 \\
\hline & & & VAV-DSW-27 \\
\hline
\end{tabular}

4.8.12 RCT: Monitor the removal of the HEPA filtered jumper.

4.8.13 Remove the HEPA filtered jumper from the CSS.

4.8.14 IF directed by supervision, THEN change out the HEPA filter as directed by RCT.

4.8.15 Install the "Dummy" sample cylinder on the CSS.

4.8.16 Close valve VAV-DSW-29.

4.8.17 RCT: Monitor the disconnecting of this equipment. 
4.8.18 Disconnect CSS inlet hose from cask port connector.

4.8.19 Install the cask pressure transducer.

4.8.20 RCT: Perform final contamination survey on all equipment and cask venting area.

\subsubsection{1 $\underline{\text { IF }}$ survey results are greater than $1,000 \mathrm{dpm} / 100 \mathrm{~cm}^{2}$ beta-gamma, THEN perform the following:}
4.8.20.1.1 $\quad$ STOP work and notify supervision and RadCon supervision for an evaluation.
4.8.20.1.2 DO NOT continue without RadCon supervision approval.

4.8.21 IF NOT proceeding to other cask activities, THEN return the equipment to the original configuration or as directed by supervision.

\subsection{Back-Filling Cask with Inert gas}

4.9.1 Ensure inert gas bottle, sample cart CRT-DSW-X, CSS, and the VDS are connected per Appendix A, Figure 1 with the VDS HEPA filtered exhaust downwind of the work area.

NOTE: The designation " $-X$ " is used to allow the component to be from sample cart CRT-DSW-1 or - 2 .

4.9.2 Ensure the following valves are closed:

\begin{tabular}{|l|c|c|l|}
\hline$\checkmark$ & $\checkmark$ & $\checkmark$ & \\
\hline & & & HCV-DSW-3-X (turn counter-clockwise to close) \\
\hline & & & NHV-DSW-2-X \\
\hline & & & NHV-DSW-1-X (on the sample cart) \\
\hline
\end{tabular}

4.9.3 Ensure inert gas bottle contains a minimum 200 psig.

Bottle Initial Pressure:

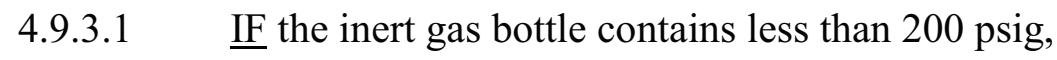
THEN change out the inert gas bottle and repeat Steps 4.9.1 through 4.9.3. 
4.9.4 Ensure that the inert gas bottle has a quality acceptance label attached.

4.9.5 IF port cover is installed on the cask, THEN remove port cover.

4.9.5.1 $\underline{\text { RCT: }}$ Perform contamination survey of newly exposed areas.

4.9.5.1.1 $\quad$ RCT: IF survey results are greater than $1,000 \mathrm{dpm} / 100 \mathrm{~cm}^{2}$ beta-gamma

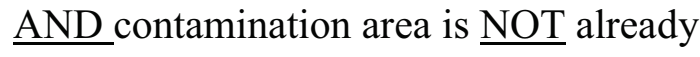
established, $\underline{\text { THEN }}$ establish a contamination area per the RWP.

\subsection{IF directed by RCT, THEN decon as directed by RCT and Supervision.}

4.9.5.2 Store cover and components.

4.9.6 IF pressure transducer is installed on the cask, THEN remove the pressure transducer.

4.9.7 Ensure the CSS inlet hose is connected to the cask port connector.

4.9.8 Ensure valve VAV-DSW-29 is open.

4.9.9 Ensure the following valves on the VDS are closed:

\begin{tabular}{|c|c|c|c|}
\hline$\checkmark$ & $\checkmark$ & $\checkmark$ & VALVE \\
\hline & & & $1-\mathrm{AV}-\mathrm{H}-0037$ \\
\hline & & & $1-\mathrm{AV}-\mathrm{GA}-0038$ \\
\hline & & & $1-\mathrm{AV}-\mathrm{H}-0039$ \\
\hline
\end{tabular}

NOTE: $\quad$ The vacuum pump 1-H-001 on the VDS needs to warm up a minimum of 30 minutes.

4.9.10 IF vacuum pump 1-H-001 on the VDS is NOT already running, THEN perform the following:

4.9.10.1 Ensure the gas ballast valve on the vacuum pump on the VDS is open (counter-clockwise to open).

4.9.10.2 Start vacuum pump 1-H-001 on the VDS.

Start time: 


\section{CPP-2707 CASK SURVEILLANCE AND SAMPLING}

Identifier: TPR-7544

Revision*: 20

Page:

4.9.11 Ensure the following valves on CSS are closed:

\begin{tabular}{|l|l|l|c|}
\hline$\checkmark$ & $\checkmark$ & $\checkmark$ & VALVE \\
\hline & & & VAV-DSW-20 \\
\hline & & & VAV-DSW-21 \\
\hline & & & VAV-DSW-23 \\
\hline & & & VAV-DSW-24 \\
\hline & & & VAV-DSW-27 \\
\hline & & & VAV-DSW-28 \\
\hline
\end{tabular}

4.9.12 Ensure the "Dummy" sample cylinder with both valves closed is installed onto the CSS.

4.9.13 Ensure the following valves on the CSS are open:

\begin{tabular}{|c|c|c|c|}
\hline$\checkmark$ & $\checkmark$ & $\checkmark$ & VALVE \\
\hline & & & VAV-DSW-24 \\
\hline & & & VAV-DSW-28 \\
\hline
\end{tabular}

4.9.14 WHEN the vacuum pump has been running a minimum of 30 minutes, THEN close the gas ballast valve on the vacuum pump (clockwise).

4.9.15 Ensure VAV-DSW-22 valve handle is positioned to the VDS label on the CSS.

4.9.16 Ensure following valves on the VDS are open:

\begin{tabular}{|c|c|c|c|}
\hline$\checkmark$ & $\checkmark$ & $\checkmark$ & VALVE \\
\hline & & & $1-\mathrm{AV}-\mathrm{H}-0037$ \\
\hline & & & $1-\mathrm{AV}-\mathrm{GA}-0038$ \\
\hline
\end{tabular}

4.9.17 RCT: Monitor HEPA filters F-DSW-103 on the CSS and the exhaust HEPA filter on the VDS during back filling activities.

4.9.18 Open valve VAV-DSW-21 on the CSS. 
4.9.19 IF a rise in radiation is detected,

THEN close VAV-DSW-21 on CSS and 1-AV-H-0037 on the VDS.

NOTE: If the radiation level rises due to noble gases, the radiation level will dissipate after valves VAV-DSW-21 on the CSS and $1-A V-H-0037$ on the VDS are CLOSED. If the radiation level rises due to particulate contamination, the radiation level will remain.

4.9.19.1 IF the source of the radiation is determined to be particulate, THEN perform the following:

4.9.19.1.1 STOP the operation in progress.

4.9.19.1.2 Notify the system engineer or the facility manager.

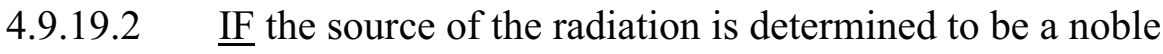
gas, THEN ensure the following:
4.9.19.2.1 VAV-DSW-21 on the CSS and 1-AV-H-0037 on the VDS are open.
4.9.19.2.2 The exhaust of vacuum pump 1-H-001 on the VDS is downwind of the work area.

4.9.20 Monitor PI-DSW-124 on the CSS.

4.9.21 WHEN PI-DSW-124 on the CSS indicates less than -11.5 psig, THEN CLOSE valve VAV-DSW-21 on the CSS and 1-AV-H-0037 on the VDS.

4.9.22 Open the gas ballast valve on the vacuum pump 1-H-001 on the VDS (counter-clockwise to open).

4.9.23 IF directed by supervision to shut down the vacuum pump, THEN shut down vacuum pump 1-H-001 on the VDS.

4.9.24 Ensure the following valves on the VDS are closed:

\begin{tabular}{|c|c|c|c|}
\hline$\checkmark$ & $\checkmark$ & $\checkmark$ & VALVE \\
\hline & & & $1-\mathrm{AV}-\mathrm{GA}-0038$ \\
\hline & & & $1-\mathrm{AV}-\mathrm{H}-0039$ \\
\hline
\end{tabular}

4.9.25 Ensure VAV-DSW-22 valve handle is positioned to inert gas supply label on the CSS. 
4.9.26 Ensure the following valves are closed:

\begin{tabular}{|l|l|l|l|}
\hline$\checkmark$ & $\checkmark$ & $\checkmark$ & \\
\hline & & & Inert gas bottle valve \\
\hline & & & HCV-DSW-3-X (turn counter-clockwise to close) \\
\hline & & & NHV-DSW-2-X \\
\hline
\end{tabular}

4.9.27 Ensure the inlet shutoff valve NHV-DSW-1-X on the sample cart is open.

4.9.28 Open inert gas bottle valve.

4.9.29 Ensure valve VAV-DSW-20 is open on the CSS.

NOTE 1: Steps 4.9.30 and 4.9.31 are performed concurrently.

NOTE 2: If inert gas regulator valve $H C V$ - $D S W-3-X$ is opened too quickly the system will overpressure outside the desired range.

4.9.30 Without exceeding 10 to 11 psi on PI-DSW-X on the sample cart, open the inert gas regulator valve HCV-DSW-3-X (turn clockwise to open).

4.9.30.1 Ensure that HCV-DSW-3-X is opened very slowly, to prevent system from over pressurizing, until pressure increase rate is determined.

4.9.30.2 IF the inert gas bottle reaches approximately 50 psig, THEN repeat Step 4.9.26.

4.9.30.2.1 Record the final pressure of the inert gas bottle.

Bottle Final Pressure:

Bottle Final Pressure:

Bottle Final Pressure:

4.9.30.2.2 Replace the inert gas bottle, and record the initial pressure of the bottle.

Bottle Final Pressure:

Bottle Final Pressure:

Bottle Initial Pressure:

4.9.30.2.3 Ensure that the inert gas bottle has a quality acceptance label attached. 


\subsection{Repeat Steps 4.9.27 through 4.9.30.}

4.9.31 WHEN PI-DSW-124 on the CSS indicates approximately -1 psig OR as directed by the supervision or facility engineer, THEN close valve VAV-DSW-20 and VAV-DSW-24.

4.9.31.1 Record time and pressure from PI-DSW-124 on the CSS.

Time: Pressure (psig):

4.9.31.2 Record the final pressure of the inert gas bottle.

Bottle Final Pressure:

4.9.32 Ensure the following valves are closed:

\begin{tabular}{|c|c|c|l|}
\hline$\checkmark$ & $\checkmark$ & $\checkmark$ & \multicolumn{1}{|c|}{ VALVE } \\
\hline & & & Inert gas bottle valve \\
\hline & & & HCV-DSW-3-X (turn counter clockwise to close) \\
\hline & & & NHV-DSW-1-X (on the sample cart) \\
\hline
\end{tabular}

4.9.33 Close valve VAV-DSW-28 on the CSS:

4.9.34 IF directed by supervision,

THEN remove CSS inlet hose from the cask port connector.

4.9.34.1 IF directed by supervision,

THEN install cask pressure transducer.

4.9.35 RCT: IF fittings will be disconnected on the equipment, THEN monitor the disconnecting of this equipment.

4.9.36 IF NOT proceeding to other cask activities, THEN return the equipment to the original configuration or as directed by supervision.

\subsection{Reinstalling Port Cover}

4.10.1 Reinstall cover over port and align bolt holes.

4.10.2 Install cover bolts hand tight.

4.10.3 IF NOT proceeding to other cask activities, THEN return the equipment to the original configuration or as directed by supervision. 


\subsection{Installing Weather Cover on Cask}

4.11.1 IF there is a gasket installed,

THEN clean and remove debris from the gasket seal surface of the weather cover and cask.

4.11.2 IF this is the VSC-17 cask

AND the gasket is NOT installed on the cask, THEN install the gasket to the cask using Loctite adhesive (part number 401) wearing nitrile gloves and safety glasses/goggles.

NOTE: Weather cover installation is an ordinary lift. The VSC-17 weather cover, COV-DSF-1, weighs 1,600 lb. The V-21 weather cover weighs $1,150 \mathrm{lb}$.

4.11.3 EO: Rig the weather cover.

NOTE 1: Steps 4.11.4 and 4.11.5 may be worked concurrently.

NOTE 2: Personnel are not allowed to reach hands, arms or other body parts under suspended load. If it is necessary to reach under to attach instruments or instrument cabling, a long reach tool needs to be used.

\section{WARNING}

Working under a suspended load is NOT authorized and may cause injury to personnel.

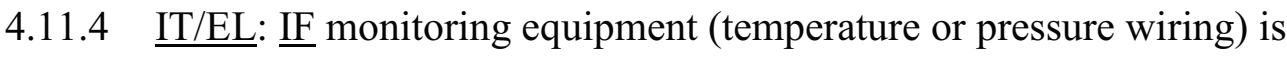
installed on the weather cover, $\underline{T H E N}$ replace the monitoring equipment using a reach tool as necessary to prevent any body parts from coming under the suspended load.

4.11.5 EO: Raise the weather cover and place per supervision direction.

4.11.6 IF bolts or tie down equipment needs installed on the weather cover, THEN install the bolts or tie down equipment.

4.11.7 IF installing the weather cover on the VSC-17 cask, THEN perform the following steps:

4.11.7.1 Obtain calibrated torque wrench(s) capable of torquing $75 \mathrm{ft} \cdot \mathrm{lb}, 100 \mathrm{ft}-\mathrm{lb}$, and $150 \mathrm{ft} \cdot \mathrm{lb}$. 
4.11.7.2 Record the information required in the following table:

\begin{tabular}{|l|l|l|l|}
\hline Torque Wrench ID Number & & & \\
\hline Calibration Due Date & & & \\
\hline Torque Wrench Range & & & \\
\hline
\end{tabular}

NOTE: $\quad$ Steps 4.11.7.3 through 4.11.7.6 are to allow for equal pressure to be applied to the weather cover gasket as it is being tightened. Only approximate torque values are required for these steps.

4.11.7.3 Appendix Set torque wrench to $75 \mathrm{ft} \bullet \mathrm{lb}$.

4.11.7.4 Torque each bolt in a star pattern as designated in A, Figure 2.

4.11.7.5 Set torque wrench to $100 \mathrm{ft} \bullet 1 \mathrm{~b}$.

4.11.7.6 Torque each bolt in a star pattern as designated in Appendix A, Figure 2.

4.11.7.7 Set torque wrench to $150 \mathrm{ft} \bullet \mathrm{lb}$.

4.11.7.8 Torque weather cover bolts to $150 \mathrm{ft} \bullet \mathrm{lb}$ in a star pattern as designated in Appendix A, Figure 2.

4.11.8 SG: IF TID is to be installed on the weather cover, THEN install the TID.

4.11.9 IF NOT proceeding to other cask activities, THEN return the equipment to the original configuration or as directed by supervision.

\subsection{Performing Post Performance Activities}

4.12.1 Clean work area.

4.12.2 Store all equipment and tools in designated area and bag out waste.

4.12.3 Supervision: perform a post-job review per MCP-3003. 
CPP-2707 CASK SURVEILLANCE AND SAMPLING

Identifier: TPR-7544

Revision*: 20

Page:

\section{RECORDS}

Consumable copies of this procedure

Form 434.14, "Pre-Job Briefing Checklist"

Form 434.15, "Pre-job Briefing Attendance Record"

NOTE: MCP-557, "Records Management," the INL Records Schedule Matrix, and associated record types list(s) provide current information on the storage, turnover, and retention requirements for these records.

\section{REFERENCES}

LST-372, "Criticality Safety Controls List for SAR-112"

MCP-1390, "Waste Generator Services Waste Management"

MCP-2692, "Ergonomics Program”

MCP-2704, "Heat and Cold Stress"

MCP-2750, "Preventing Disease from Rodents, Birds and Bats"

MCP-3003, "Performing Pre-job Briefings and Documenting Feedback"

PRD-650, "ICP Hoisting and Rigging Requirements"

PRD-5107, "Aerial Lifts and Elevating Work Platforms"

SAR-112, "Safety Analysis Report for the Underground Fuel Storage Facility"

TSR-112, "Technical Safety Requirements for the Underground Fuel Storage Facility"

\section{APPENDIXES}

Appendix A, Figures

Appendix B, Procedure Hazard Analysis

Appendix C, Procedure Basis 


\section{Appendix A}

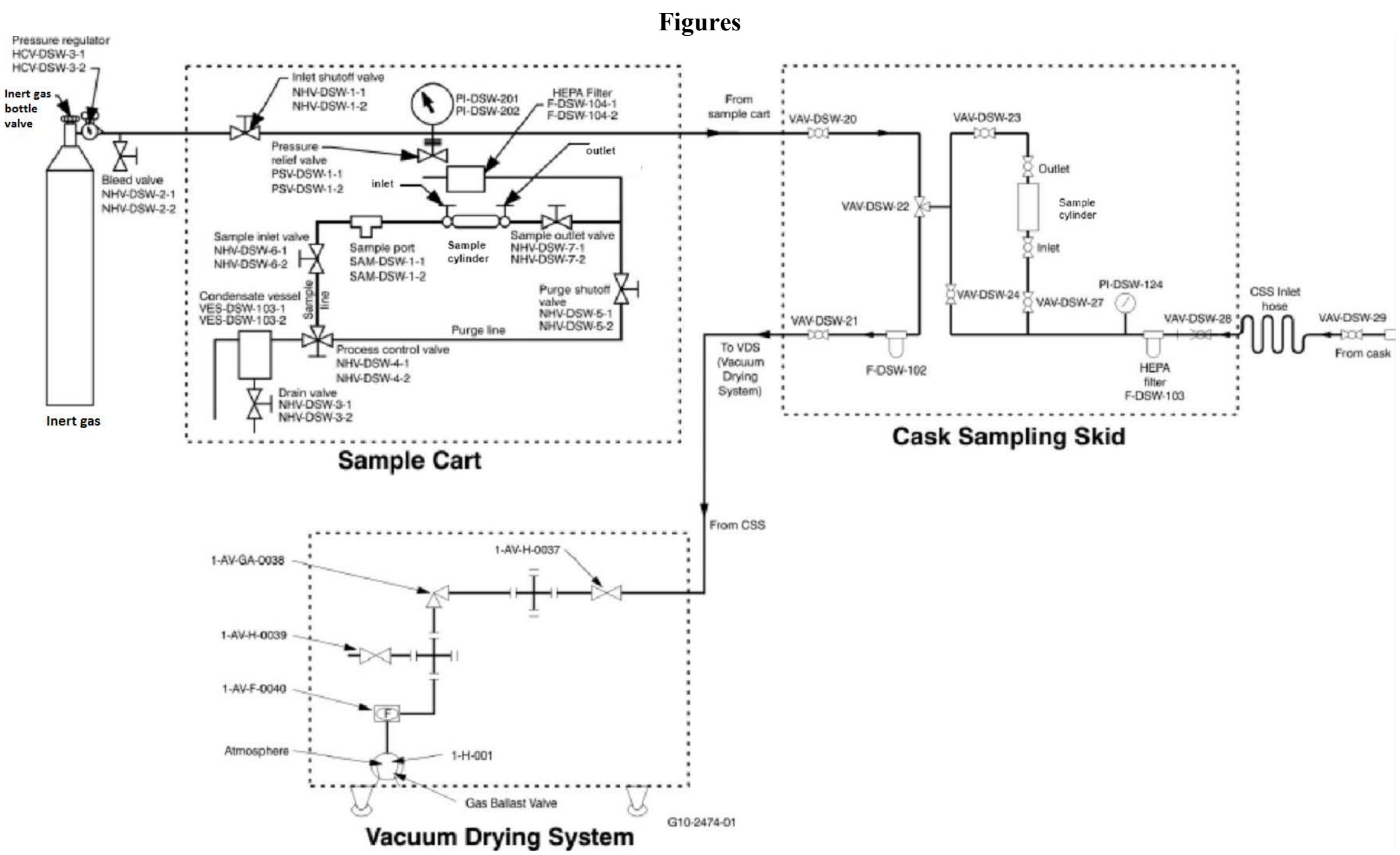

Figure 1. Sample cart CRT-DSW-X, cask sampling skid, and vacuum drying system. 


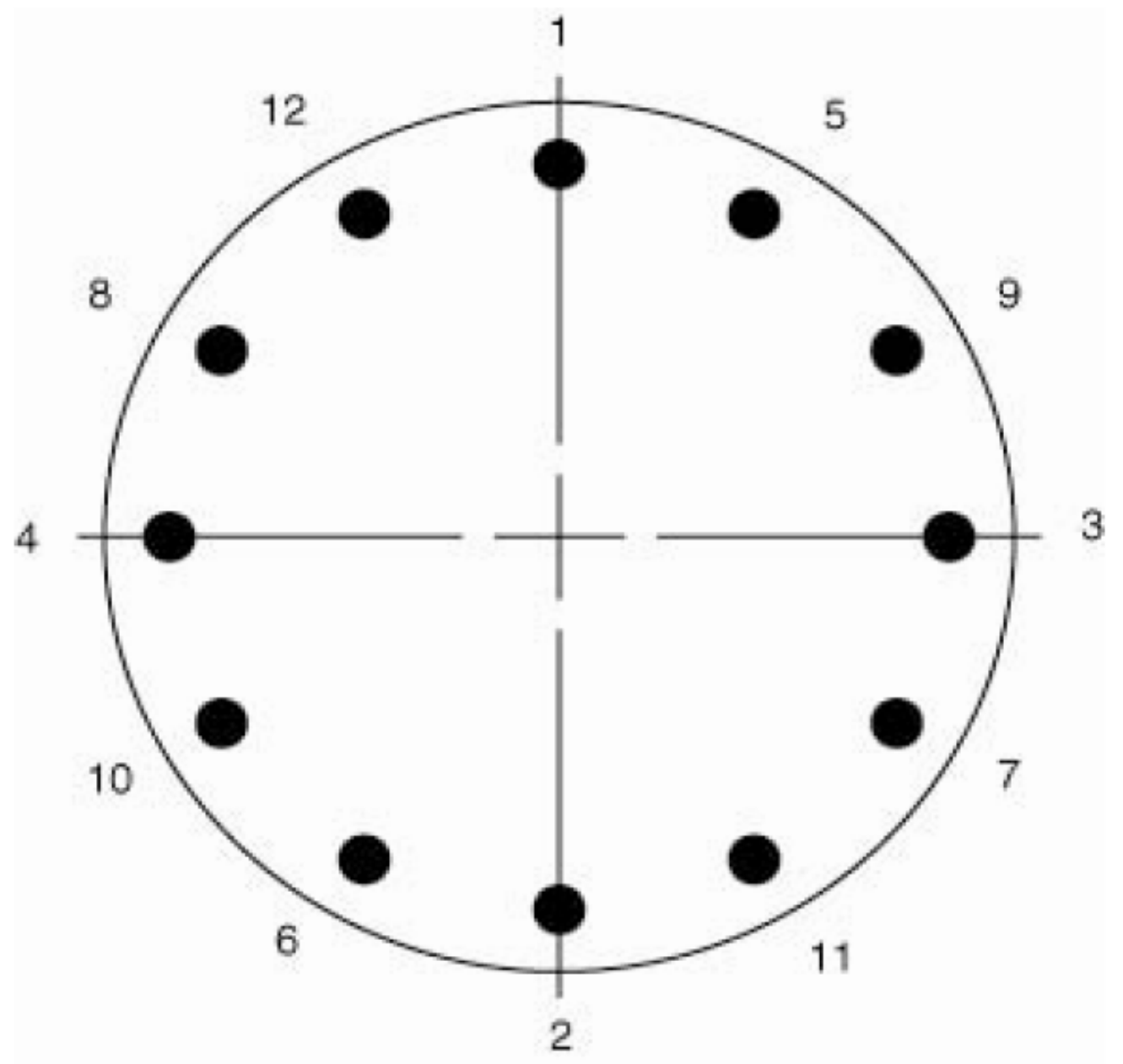

12 bolt lid

Figure 2. VSC-17 weather cover torque pattern. 


\section{Appendix B}

\section{Procedure Hazard Analysis}

\begin{tabular}{|c|c|c|c|c|c|}
\hline \multicolumn{4}{|c|}{ Highly Hazardous Activity? $\square$ Yes $\bigotimes$ No } & \multicolumn{2}{|c|}{ HPSC No.: JSA-1655 } \\
\hline \multicolumn{6}{|c|}{$\begin{array}{l}\text { Disciplines (SMEs) involved in hazard analysis: (Checking the box indicates discipline is/was involved in the hazard analysis for this } \\
\text { procedure.) }\end{array}$} \\
\hline & Discipline & & Discipli & & Discipline \\
\hline$\bigotimes$ & Industrial Safety & $\bigotimes$ & RCT/RAD Eng. & $\bigotimes$ & Engineering \\
\hline$\bigotimes$ & Industrial Hygiene & 区 & Env. Protection & 凶 & Operations \\
\hline$\bigotimes$ & Fire Protection & $\bigotimes$ & Quality Assuranc & $\square$ & Other: \\
\hline \multicolumn{6}{|c|}{ Required Job Training/Required Personal Protective Equipment } \\
\hline \multicolumn{3}{|c|}{ Training } & \multicolumn{3}{|r|}{ PPE } \\
\hline \multicolumn{3}{|c|}{ Radiological worker II } & \multicolumn{3}{|l|}{ Hand Protection } \\
\hline \multicolumn{3}{|c|}{ Certified Fuel Handler } & \multicolumn{3}{|c|}{ Safety glasses or goggles } \\
\hline \multicolumn{3}{|c|}{ Heat/Cold Stress } & \multicolumn{3}{|c|}{ Hearing protection (if in close proximity) } \\
\hline \multicolumn{3}{|c|}{ Ladder Safety } & \multicolumn{3}{|c|}{ Substantial footwear with protective toe caps } \\
\hline \multicolumn{3}{|c|}{ Aerial Lift (as required) } & \multicolumn{3}{|c|}{ Nitrile gloves } \\
\hline \multicolumn{3}{|c|}{ Compressed Gas } & & & \\
\hline \multicolumn{3}{|c|}{ Fall Protection } & & & \\
\hline
\end{tabular}

\begin{tabular}{|c|c|c|c|c|c|}
\hline \multicolumn{2}{|c|}{ Sequence of Basic Job Steps } & \multicolumn{2}{|r|}{ Potential Hazards } & \multicolumn{2}{|r|}{ Hazard Control/PPE } \\
\hline & \multirow{6}{*}{$\begin{array}{l}\text { General requirements } \\
\text { (hazards applicable to the } \\
\text { whole procedure) }\end{array}$} & & Weather conditions & & $\begin{array}{l}\text { Technical Lead (TL) must evaluate weather } \\
\text { conditions for the tasks to be performed. }\end{array}$ \\
\hline & & $1 b$. & Manual lifting & $1 b$. & $\begin{array}{l}\text { Proper lifting techniques must be used per } \\
\text { MCP-2692, "Ergonomics Program." }\end{array}$ \\
\hline & & & Body positioning & 1c. & $\begin{array}{l}\text { Body positioning during bolt tightening and } \\
\text { loosening activities must be used per MCP- } 2692 \text {. }\end{array}$ \\
\hline & & $1 \mathrm{~d}$. & Aerial lifts & & $\begin{array}{l}\text { Aerial lift operator training is required to run the } \\
\text { lift. Others in the lift will require fall protection } \\
\text { training. }\end{array}$ \\
\hline & & 1e. & Heat/cold stress & & $\begin{array}{l}\text { Heat/cold stress stay times must be followed per } \\
\text { MCP-2704, "Heat and Cold Stress." }\end{array}$ \\
\hline & & & Waste generation & $1 \mathrm{f}$. & $\begin{array}{l}\text { All waste will be approved and disposed per } \\
\text { MCP-1390, "Waste Generator Services Waste } \\
\text { Management." }\end{array}$ \\
\hline \multirow{3}{*}{\multicolumn{2}{|c|}{$\begin{array}{l}\text { 2. Performing purge of cask } \\
\text { sampling skid }\end{array}$}} & & $\begin{array}{l}\text { Tripping } \\
\text { hazard/uneven } \\
\text { walking working } \\
\text { surface, dropped/ } \\
\text { falling object }\end{array}$ & $2 \mathrm{a}$. & $\begin{array}{l}\text { Operator to be briefed on the tripping hazards } \\
\text { around the casks. Substantial footwear with } \\
\text { protective toe caps required for work in areas where } \\
\text { dropped/falling objects, tripping hazards, or uneven } \\
\text { surfaces exist. }\end{array}$ \\
\hline & & $2 b$. & Radiological & $2 b$. & $\begin{array}{l}\text { RWP, briefed on radiological/contamination levels, } \\
\text { Radiological postings and training. }\end{array}$ \\
\hline & & $2 \mathrm{c}$. & Pinching & & $\begin{array}{l}\text { Leather gloves must be worn when manipulating } \\
\text { valves and connecting equipment. }\end{array}$ \\
\hline
\end{tabular}




\section{CPP-2707 CASK SURVEILLANCE AND SAMPLING}

Identifier: TPR-7544

Revision*: 20

Page: $\quad \mathbf{4 3}$ of 48

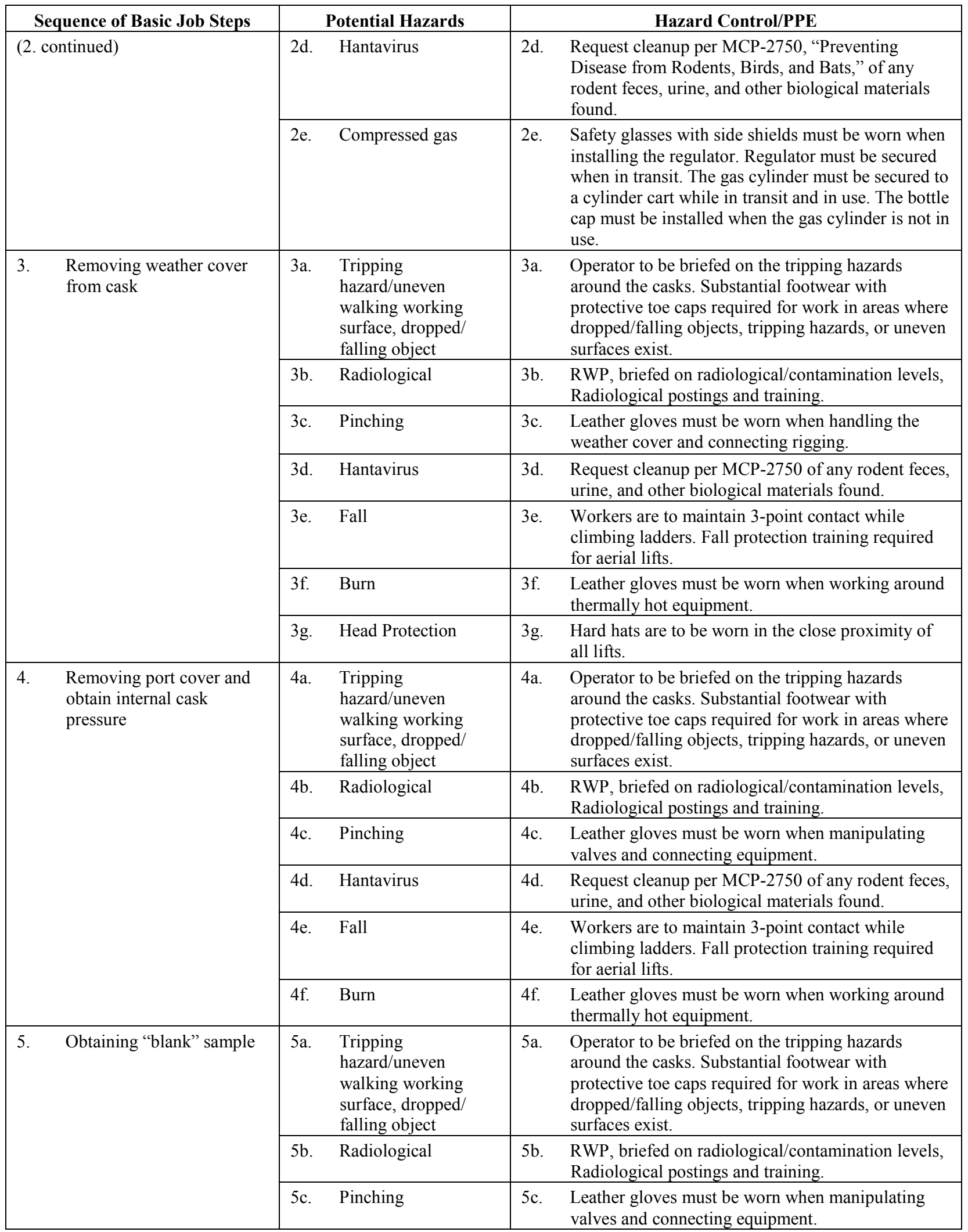




\section{CPP-2707 CASK SURVEILLANCE AND SAMPLING}

Identifier: TPR-7544

Revision*: 20

Page:
44 of 48

\begin{tabular}{|c|c|c|}
\hline Sequence of Basic Job Steps & Potential Hazards & Hazard Control/PPE \\
\hline \multirow[t]{5}{*}{ (5. continued) } & 5d. Hantavirus & $\begin{array}{l}\text { 5d. Request cleanup per MCP-2750 of any rodent feces, } \\
\text { urine, and other biological materials found. }\end{array}$ \\
\hline & Burn & $\begin{array}{l}\text { 5e. Leather gloves must be worn when working around } \\
\text { thermally hot equipment. }\end{array}$ \\
\hline & Electrical & GFCI must be used with electrical equipment. \\
\hline & 5g. Noise & $\begin{array}{l}\text { 5g. Hearing protection must be utilized in close } \\
\text { proximity to generator and VDS. }\end{array}$ \\
\hline & Compressed gas & $\begin{array}{l}\text { 5h. Safety glasses with side shields must be worn when } \\
\text { installing the regulator. Regulator must be secured } \\
\text { when in transit. The gas cylinder must be secured to } \\
\text { a cylinder cart while in transit and in use. The bottle } \\
\text { cap must be installed when the gas cylinder is not in } \\
\text { use. }\end{array}$ \\
\hline \multirow[t]{7}{*}{ 6. Venting the cask } & $\begin{array}{l}\text { Tripping } \\
\text { hazard/uneven } \\
\text { walking working } \\
\text { surface, dropped/ } \\
\text { falling object }\end{array}$ & $\begin{array}{l}\text { Operator to be briefed on the tripping hazards } \\
\text { around the casks. Substantial footwear with } \\
\text { protective toe caps required for work in areas where } \\
\text { dropped/falling objects, tripping hazards, or uneven } \\
\text { surfaces exist. }\end{array}$ \\
\hline & Radiological & $\begin{array}{l}\text { 6b. RWP, briefed on radiological/contamination levels, } \\
\text { Radiological postings and training. }\end{array}$ \\
\hline & 6c. Pinching & $\begin{array}{l}\text { 6c. Leather gloves must be worn when manipulating } \\
\text { valves and connecting equipment. }\end{array}$ \\
\hline & 6d. Hantavirus & $\begin{array}{l}\text { 6d. Request cleanup per MCP-2750 of any rodent feces, } \\
\text { urine, and other biological materials found. }\end{array}$ \\
\hline & 6e. Burn & $\begin{array}{l}\text { 6e. Leather gloves must be worn when working around } \\
\text { thermally hot equipment. }\end{array}$ \\
\hline & $\begin{array}{ll}\text { 6f. } & \text { Environmental } \\
& \text { Releases } \\
\end{array}$ & $\begin{array}{l}\text { 6f. If particulate radiological air emissions are } \\
\text { discovered, all work will be stopped and evaluated. }\end{array}$ \\
\hline & 6g. Fall & $\begin{array}{l}\text { 6g. Workers are to maintain 3-point contact while } \\
\text { climbing ladders. Fall protection training required } \\
\text { for aerial lifts. }\end{array}$ \\
\hline \multirow[t]{8}{*}{$\begin{array}{l}\text { 7. Backfilling cask with inert } \\
\text { gas }\end{array}$} & $\begin{array}{ll}\text { 7a. } & \text { Tripping } \\
\text { hazard/uneven } \\
\text { walking working } \\
\text { surface, dropped/ } \\
\text { falling object } \\
\end{array}$ & $\begin{array}{l}\text { 10a. Operator to be briefed on the tripping hazards } \\
\text { around the casks. Substantial footwear with } \\
\text { protective toe caps required for work in areas where } \\
\text { dropped/falling objects, tripping hazards or uneven } \\
\text { surfaces exist. }\end{array}$ \\
\hline & 7b. Radiological & $\begin{array}{l}\text { 7b. RWP, briefed on radiological/contamination levels, } \\
\text { Radiological postings and training. }\end{array}$ \\
\hline & 7c. $\quad$ Pinching & $\begin{array}{l}\text { 7c. Leather gloves must be worn when manipulating } \\
\text { valves and connecting equipment. }\end{array}$ \\
\hline & 7d. Hantavirus & $\begin{array}{l}\text { 7d. Request cleanup per MCP-2750 of any rodent feces, } \\
\text { urine, and other biological materials found. }\end{array}$ \\
\hline & 7e. Burn & $\begin{array}{l}\text { 7e. Leather gloves must be worn when working around } \\
\text { thermally hot equipment. }\end{array}$ \\
\hline & Electrical & GFCI must be used with electrical equipment. \\
\hline & 7g. Noise & $\begin{array}{l}\text { 7g. Hearing protection must be utilized in close } \\
\text { proximity to generator and VDS. }\end{array}$ \\
\hline & 7h. Compressed gas & $\begin{array}{l}\text { 7h. Safety glasses with side shields must be worn when } \\
\text { installing the regulator. Regulator must be secured } \\
\text { when in transit. The gas cylinder must be secured to } \\
\text { a cylinder cart while in transit and in use. The bottle } \\
\text { cap must be installed when the gas cylinder is not in } \\
\text { use. }\end{array}$ \\
\hline
\end{tabular}




\section{CPP-2707 CASK SURVEILLANCE AND SAMPLING}

\begin{tabular}{|ll|} 
Identifier: & TPR-7544 \\
Revision*: & 20 \\
Page: & $\mathbf{4 5}$ of 48 \\
\hline
\end{tabular}

\begin{tabular}{|c|c|c|}
\hline Sequence of Basic Job Steps & Potential Hazards & Hazard Control/PPE \\
\hline \multirow[t]{2}{*}{ (7. continued) } & $\begin{array}{ll}\text { 7i. } & \begin{array}{l}\text { Environmental } \\
\text { releases }\end{array} \\
\end{array}$ & $\begin{array}{l}\text { 7i. If particulate radiological air emissions are } \\
\text { discovered, all work will be stopped and evaluated. }\end{array}$ \\
\hline & Fall & $\begin{array}{l}\text { 7j. Workers are to maintain 3-point contact while } \\
\text { climbing ladders. Fall protection training required } \\
\text { for aerial lifts. }\end{array}$ \\
\hline \multirow[t]{7}{*}{ 8. Reinstalling port cover } & $\begin{array}{l}\text { Tripping } \\
\text { hazard/uneven } \\
\text { walking working } \\
\text { surface, dropped/ } \\
\text { falling object }\end{array}$ & $\begin{array}{l}\text { 8a. Operator to be briefed on the tripping hazards } \\
\text { around the casks. Substantial footwear with } \\
\text { protective toe caps required for work in areas where } \\
\text { dropped/falling objects, tripping hazards, or uneven } \\
\text { surfaces exist. }\end{array}$ \\
\hline & Radiological & $\begin{array}{l}\text { 8b. RWP, briefed on radiological/contamination levels, } \\
\text { Radiological postings and training. }\end{array}$ \\
\hline & Pinching & $\begin{array}{l}\text { 8c. Leather gloves must be worn when manipulating } \\
\text { valves and connecting equipment. }\end{array}$ \\
\hline & 8d. Hantavirus & $\begin{array}{l}\text { 8d. Request cleanup per MCP-2750 of any rodent feces, } \\
\text { urine, and other biological materials found. }\end{array}$ \\
\hline & Burn & $\begin{array}{l}\text { 8e. Leather gloves must be worn when working around } \\
\text { thermally hot equipment. }\end{array}$ \\
\hline & Chemical & $\begin{array}{l}\text { Nitrile gloves and safety glasses or goggles must be } \\
\text { worn when using Never-Seize or Loctite Adhesive. }\end{array}$ \\
\hline & Fall & $\begin{array}{l}\text { 8g. Workers are to maintain 3-point contact while } \\
\text { climbing ladders. Fall protection training required } \\
\text { for aerial lifts. }\end{array}$ \\
\hline \multirow[t]{8}{*}{$\begin{array}{l}\text { 9. Installing the weather cover } \\
\text { on cask }\end{array}$} & $\begin{array}{l}\text { Tripping } \\
\text { hazard/uneven } \\
\text { walking working } \\
\text { surface, dropped/ } \\
\text { falling object }\end{array}$ & $\begin{array}{l}\text { 9a. Operator to be briefed on the tripping hazards } \\
\text { around the casks. Substantial footwear with } \\
\text { protective toe caps required for work in areas where } \\
\text { dropped/falling objects, tripping hazards, or uneven } \\
\text { surfaces exist. }\end{array}$ \\
\hline & Radiological & $\begin{array}{l}\text { 9b. RWP, briefed on radiological/contamination levels, } \\
\text { Radiological postings and training. }\end{array}$ \\
\hline & Pinching & $\begin{array}{l}\text { 9c. Leather gloves must be worn when handling the } \\
\text { weather cover and connecting rigging. }\end{array}$ \\
\hline & Hantavirus & $\begin{array}{l}\text { 9d. Request cleanup per MCP- } 2750 \text { of any rodent feces, } \\
\text { urine, and other biological materials found. }\end{array}$ \\
\hline & Fall & $\begin{array}{l}\text { 9e. Workers are to maintain 3-point contact while } \\
\text { climbing ladders. Fall protection training required } \\
\text { for aerial lifts. }\end{array}$ \\
\hline & Burn & $\begin{array}{l}\text { 9f. Leather gloves must be worn when working around } \\
\text { thermally hot equipment. }\end{array}$ \\
\hline & Head Protection & $\begin{array}{l}\text { 9g. Hard hats are to be worn in the close proximity of } \\
\text { all lifts. }\end{array}$ \\
\hline & 9h. Chemical & $\begin{array}{l}\text { 9h. Nitrile gloves and safety glasses or goggles must be } \\
\text { worn when using Never-Seize or Loctite Adhesive. }\end{array}$ \\
\hline
\end{tabular}




\section{Appendix C}

\section{Procedure Basis}

\begin{tabular}{|c|c|c|c|c|c|c|c|}
\hline \multicolumn{8}{|c|}{ Procedure Review Table } \\
\hline $\begin{array}{c}\text { Review } \\
\text { Discipline }\end{array}$ & Rev. & $\begin{array}{c}\text { DFC } \\
\text { Intent }^{b} \\
\text { Change }\end{array}$ & $\begin{array}{c}\text { DFC } \\
\text { Nonintent }^{\mathrm{c}} \\
\text { Change } \\
\end{array}$ & $\begin{array}{c}\text { Review } \\
\text { Discipline }\end{array}$ & Rev. & $\begin{array}{c}\text { DFC } \\
\text { Intent }^{\mathrm{b}} \\
\text { Change }\end{array}$ & $\begin{array}{c}\text { DFC } \\
\text { Nonintent }^{\mathrm{c}} \\
\text { Change } \\
\end{array}$ \\
\hline $\begin{array}{l}\text { Operations } \\
\text { Management }\end{array}$ & $X^{a}$ & $\mathrm{X}$ & $\mathrm{X}$ & $\begin{array}{l}\text { Industrial } \\
\text { Safety }\end{array}$ & & & \\
\hline $\begin{array}{l}\text { Qualified } \\
\text { Operator }\end{array}$ & $\mathrm{X}$ & $\mathrm{X}$ & $\mathrm{X}$ & Engineering & $\mathrm{X}$ & $\mathrm{X}$ & $*$ \\
\hline $\begin{array}{l}\text { Radiological } \\
\text { Engineering }\end{array}$ & $X$ & $\mathrm{X}$ & $*$ & $\begin{array}{l}\text { Industrial } \\
\text { Hygiene }\end{array}$ & & & \\
\hline Environmental & $X$ & $X$ & $*$ & Other: S\&H & $X$ & $X$ & $*$ \\
\hline Quality & $X$ & $\mathrm{X}$ & $*$ & $\mathrm{CSO}$ & $\mathrm{X}$ & $\mathrm{X}$ & $*$ \\
\hline $\begin{array}{l}\text { Nuclear } \\
\text { Facility } \\
\text { Manager }\end{array}$ & $\mathrm{X}$ & $\mathrm{X}$ & $\mathrm{X}$ & & & & \\
\hline \multicolumn{8}{|c|}{$\begin{array}{l}\text { a. } X=\text { review required. } \\
\text { b. Reviews for intent DFCs require the same discipline reviews required for a revision. } \\
\text { c. Reviews for nonintent DFCs can be performed with only Operations management and a qualified operator's } \\
\text { review and then implemented for immediate use. However, the remaining discipline reviews, as indicated by an } \\
\text { asterisk }(*) \text { must be obtained within two (2) weeks. See MCP-2985, "Chapter XVI - Operations Procedures," for } \\
\text { definitions of intent and nonintent changes. }\end{array}$} \\
\hline
\end{tabular}

\begin{tabular}{|c|l|l|l|}
\hline Step & \multicolumn{1}{|c|}{ Basis } & \multicolumn{1}{|c|}{ Source } & Citation \\
\hline 2.1 & $\begin{array}{l}\text { Weather conditions (sustained wind greater than } \\
\text { 25 mph for lifting activities, rain, lightning, and } \\
\text { so forth) must be evaluated by supervision to } \\
\text { determine whether or not procedure operations } \\
\text { can continue or if a safe holding point needs to be } \\
\text { identified and operations stopped at that point. }\end{array}$ & $\begin{array}{l}\text { Best Operational } \\
\text { Practice }\end{array}$ & \\
\hline 2.2 & $\begin{array}{l}\text { Personnel must follow the applicable hazard } \\
\text { mitigations detailed in Appendix B, Procedure } \\
\text { Hazard Analysis. }\end{array}$ & $\begin{array}{l}\text { Procedure } \\
\text { hazards analysis }\end{array}$ & \\
\hline 2.3 & $\begin{array}{l}\text { If 110V electrical power is needed a ground fault } \\
\text { circuit interrupter (GFCI) must be used on 110V }\end{array}$ & $\begin{array}{l}\text { Procedure } \\
\text { hazards analysis }\end{array}$ & \\
\hline
\end{tabular}


CPP-2707 CASK SURVEILLANCE AND SAMPLING

Identifier: TPR-7544

Revision*: 20

Page:

47 of 48

\begin{tabular}{|c|c|c|c|}
\hline Step & Basis & Source & Citation \\
\hline & equipment for personnel protection. & & \\
\hline 2.4 & $\begin{array}{l}\text { Aerial lifts must be operated in accordance with } \\
\text { PRD-5107. }\end{array}$ & $\begin{array}{l}\text { Procedure } \\
\text { hazards analysis }\end{array}$ & \\
\hline 2.5 & $\begin{array}{l}\text { Hard hats must be worn when working near } \\
\text { (within } 25 \mathrm{ft} \text { ) an operating mobile crane or } \\
\text { suspended load. Hard hats must be worn when } \\
\text { working within the roped off area of an operating } \\
\text { scissor lift or man lift. }\end{array}$ & $\begin{array}{l}\text { Procedure } \\
\text { hazards analysis }\end{array}$ & \\
\hline 2.6 & $\begin{array}{l}\text { Hoisting and rigging must be performed in } \\
\text { compliance with requirements established in } \\
\text { PRD-650. }\end{array}$ & PRD-650 & \\
\hline 2.7 & $\begin{array}{l}\text { Lifting or moving fuel-loaded casks on the } \\
\text { CPP-2707 pad is not an activity that is authorized. }\end{array}$ & SAR-112 & Chapter 3 \\
\hline 2.8 & $\begin{array}{l}\text { Pressure regulator HCV-DSW-3-1 or - } 2 \text { must be } \\
\text { adjusted periodically to correct drift in gas } \\
\text { pressure during operation, as required. }\end{array}$ & $\begin{array}{l}\text { Best Operational } \\
\text { Practice }\end{array}$ & \\
\hline 2.9 & $\begin{array}{l}\text { Radiological Control Technician coverage must } \\
\text { be used when breaking open transfer lines, piping } \\
\text { and any line suspected to be internally } \\
\text { contaminated. }\end{array}$ & $\begin{array}{l}\text { Radiological } \\
\text { requirement }\end{array}$ & \\
\hline $3.1 .2 \mathrm{~A}$ & $\begin{array}{l}\text { A minimum of at least one certified fuel handler } \\
\text { at the UGFSF shall be present and responsible } \\
\text { when performing the following operations: } \\
\text { Removal of fuel-loaded fuel storage vault lid } \\
\text { or shield plug } \\
\text { Removal of the fuel-loaded cask lid or cask lid } \\
\text { shield plug } \\
\text { Operations including: fuel-loaded storage vault } \\
\text { inspections, installation of lift rods or support } \\
\text { plates, and fuel handling that are performed } \\
\text { without the vault lid, vault shield plug, cask } \\
\text { lid, or cask shield plug in place } \\
\text { Operations involving loading or unloading fuel } \\
\text { per the CAFL or CACL also require the } \\
\text { presence of a second person certified in fuel } \\
\text { handling to perform verifications. }\end{array}$ & TSR-112 & $\begin{array}{l}\text { LCO 3.112.2 } \\
\text { AC 5.112.1A } \\
\text { LST-372 }\end{array}$ \\
\hline
\end{tabular}


CPP-2707 CASK SURVEILLANCE AND SAMPLING

Identifier: TPR-7544

Revision*: 20

Page:

48 of 48

\begin{tabular}{|c|c|c|c|}
\hline Step & Basis & Source & Citation \\
\hline $3.1 .2 \mathrm{C}$ & $\begin{array}{l}\text { A minimum of at least one qualified crane } \\
\text { operator shall be present and responsible during } \\
\text { the following fuel handling operations: } \\
\text { 1. Crane operation } \\
\text { 2. Fuel-loaded cask handling operations. }\end{array}$ & TSR-112 & $\begin{array}{l}\text { LCO } 3.112 .2 \\
\text { AC 5.112.1B } \\
\text { LST-372 }\end{array}$ \\
\hline 3.4 .1 & $\begin{array}{l}\text { Ensure personnel performing this procedure have } \\
\text { completed the following training, as applicable: } \\
\text { A. Certified Fuel Handler } \\
\text { B. Radiological Worker II } \\
\text { C. Heat/Cold Stress } \\
\text { D. Hantavirus Awareness } \\
\text { E. Ladder Safety (as required) } \\
\text { F. Aerial Lift (as required) } \\
\text { G. Compressed Gas (if handling, transporting, } \\
\text { H. Fall Protection (as required) } \\
\text { I. Torque wrench. }\end{array}$ & $\begin{array}{l}\text { Procedure } \\
\text { hazards analysis }\end{array}$ & \\
\hline $\begin{array}{l}4.7 .36 \\
4.7 .54\end{array}$ & $\begin{array}{l}\text { Cask atmosphere sampling (hydrogen, volatile } \\
\text { organic vapors, air components) flammable gas } \\
\text { generation causes seal failure. Periodic sampling } \\
\text { is necessary in specified casks where flammable } \\
\text { gas generation has been demonstrated due to the } \\
\text { presence of water or previous monitoring. } \\
\text { REA-2023: } 6 \text { mo, VSC-17: } 3 \mathrm{yr} \text {, NuPac } 125 \mathrm{~B}-2 \text { : } \\
1 \text { yr or when opened, TN-24P, V/21 and MC-10: } \\
5 \text { year }\end{array}$ & PLN-1720 & Appendix B \\
\hline
\end{tabular}

